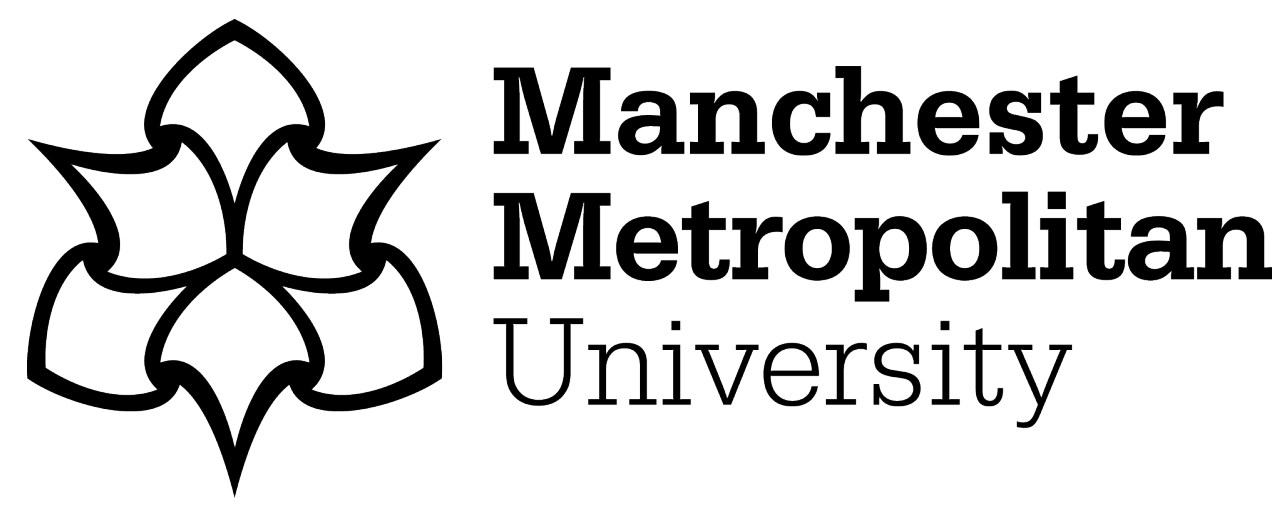

Ray, Daniel, Collins, Tim ORCID logoORCID: https://orcid.org/0000-00032841-1947, Woolley, Sandra and Ponnapalli, Prasad (2023) A Review of Wearable Multi-wavelength Photoplethysmography. IEEE Reviews in Biomedical Engineering, 16. pp. 136-151. ISSN 1937-3333

Downloaded from: https://e-space.mmu.ac.uk/628692/

Version: Accepted Version

Publisher: Institute of Electrical and Electronics Engineers (IEEE)

DOI: https://doi.org/10.1109/rbme.2021.3121476

Please cite the published version 


\title{
A Review of Wearable Multi-wavelength Photoplethysmography
}

\author{
Daniel Ray (Student Member, IEEE), Tim Collins (Senior Member, IEEE), Sandra I. Woolley (Senior \\ Member, IEEE), and Prasad V. S. Ponnapalli (Member, IEEE)
}

\begin{abstract}
Optical pulse detection 'photoplethysmography' (PPG) provides a means of low cost and unobtrusive physiological monitoring that is popular in many wearable devices. However, the accuracy, robustness and generalizability of single-wavelength PPG sensing are sensitive to biological characteristics as well as sensor configuration and placement; this is significant given the increasing adoption of single-wavelength wrist-worn PPG devices in clinical studies and healthcare. Since different wavelengths interact with the skin to varying degrees, researchers have explored the use of multi-wavelength PPG to improve sensing accuracy, robustness and generalizability. This paper contributes a novel and comprehensive state-of-the-art review of wearable multi-wavelength PPG sensing, encompassing motion artifact reduction and estimation of physiological parameters. The paper also encompasses theoretical details about multi-wavelength PPG sensing and the effects of biological characteristics. The review findings highlight the promising developments in motion artifact reduction using multi-wavelength approaches, the effects of skin temperature on PPG sensing, the need for improved diversity in PPG sensing studies and the lack of studies that investigate the combined effects of factors. Recommendations are made for the standardization and completeness of reporting in terms of study design, sensing technology and participant characteristics.
\end{abstract}

Index Terms - Multi-wavelength Photoplethysmography, Skin Optics, Skin Melanin, Skin Temperature, Motion Artifact Reduction, Physiological Monitoring.

\section{INTRODUCTION}

$\mathbf{T}$ HE current passive paradigm of late-stage treatment of chronic diseases is transitioning towards more proactive and preventative measures, such as cost-effective continuous monitoring tools to support early prediction, early prevention, early diagnosis and early treatment [1]. The World Health Organization (WHO) have recommended continuous monitoring as an effective means to assess physiological conditions,

Manuscript received April 26, 2021; revised August 03, 2021; accepted September 22, 2021. This research received no external funding.

D. Ray is with the Department of Engineering, Manchester Metropolitan University, Manchester, UK (e-mail: Daniel.Ray@stu.mmu.ac.uk ).

T. Collins is with the Department of Engineering, Manchester Metropolitan University, Manchester, UK (e-mail: T.Collins@mmu.ac.uk).

S. I. Woolley is with the School of Computing and Mathematics, Keele University, Staffordshire, UK (e-mail: S.I.Woolley@keele.ac.uk).

P. V. S. Ponnapalli is with the Department of Engineering, Manchester Metropolitan University, Manchester, UK (e-mail: P.Ponnapalli@mmu.ac.uk). monitor the progression of diseases and support daily selfmanagement of health [2].

Clinically performed electrocardiography (ECG), such as the conventional 12-lead ECG acquisition, is widely considered the 'gold standard' of non-invasive cardiovascular monitoring. ECG can identify cardiovascular abnormalities and detect irregularities in heart rhythms as well as performing physiological assessments of Heart Rate (HR) and Heart Rate Variability (HRV) by recording the depolarization of the heart's conductive pathway and the surrounding cardiac muscle tissues during each cardiac cycle. Although accurate, multi-lead clinical ECG is unsuited to continuous monitoring. It lacks portability, and convenience, and the bio-electrodes are obtrusive, cannot get wet and must be placed at specific locations on the body and connected to a recording device [3].

Consumer health monitoring devices have underpinned growth in the wearable devices market, a market expected to reach $\$ 30$ billion by the end of 2023 [4], and the maturation of low cost, unobtrusive sensing devices incorporating optical pulse detection 'photoplethysmography' (PPG) sensors [3], [5]. A sensing method similar to PPG sensing was first devised in 1936 by two American research groups [6], but it was Alrick Hertzman who established PPG sensing in 1937 [7]. Consisting of a light source and photo-detector, light is emitted into the skin and the intensity of light transmitted into the photo-detector will vary depending on the volume of blood in the vascular bed of the measurement site, taking advantage of blood's absorbent qualities to visible and infrared (IR) light. During the contraction of the left ventricle, blood is ejected out of the heart and propagates along the circulatory system, corresponding to the initial positive slope of a PPG pulse (Figure 1). The systolic peak marks the maximum amount of blood present in the vascular bed at the measurement site. The pulse waveform then decreases in amplitude until a local minimum where it transitions into the diastolic phase. The local minimum or dicrotic notch marks the closure of the aortic valves. The end of the diastolic phase marks the closure mitral valve [8]. As well as the $\mathrm{AC}$ or pulsatile component of the signal, PPG sensing also collects the DC or non-pulsatile component which is shaped by respiration, sympathetic nervous system activity, and thermoregulation [3].

There are two modes of PPG sensing with different measurement sites (Figure 2). Transmission PPG sensors are usually sited on the fingertip or earlobe where the light source and detector are separated by tissue. Reflectance PPG sensors, 


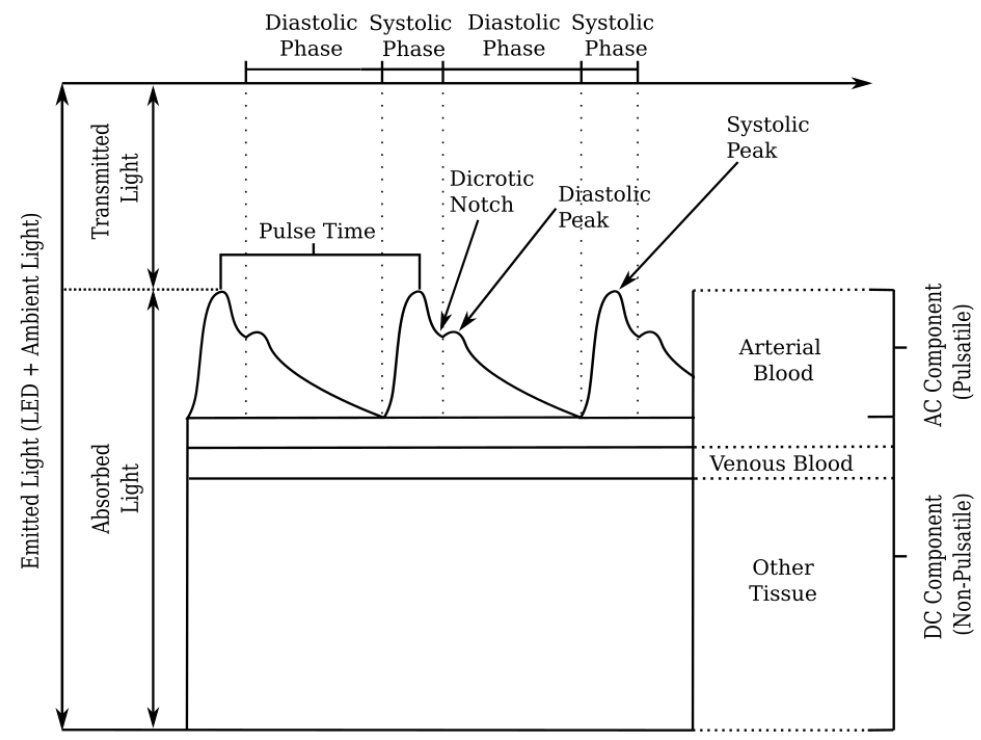

Fig. 1: A typical PPG waveform adapted from Lemay et al. [34].

which have both components positioned alongside each other on the same side of tissue, are commonly sited on the wrist, forehead or torso [3]. Both reflectance and transmission PPG sensing can provide physiological insights for HR [5], Blood Oxygen Saturation $\left(\mathrm{SpO}_{2}\right)$ [9], Respiration Rate [10], Vascular Aging and Atherosclerosis [3], [11], Blood Pressure (BP) [12] which is an indicator for Hypertension [13] and Atrial Fibrillation as well as HRV which itself provides indications about Coronary Heart Disease [14] and Autonomic Nervous System functionality [15].

Although transmission mode PPG sensing is widely used in clinical settings for pulse oximetry measurements, reflectance mode PPG and PPG sensing for other physiological measurements has not been widely adopted in clinical practice. One of the main factors affecting PPG sensing performance is its susceptibility to interference, predominantly from motion artifacts [16]. Other significant factors affecting the performance include the amount of blood flowing into the peripheral vascular bed, the varying optical properties of skin and blood, ambient light, and the wavelength used to illuminate the skin [5]. Addressing these factors would produce a low cost, simple and unobtrusive method to accurately, robustly and continuously measure the physiological status of patients having the potential to reduce premature mortality and the economic burden of disease and illness.

Beyond cardiovascular monitoring and general well-being, PPG sensing has seen several developments including the detection and monitoring of epileptic seizures [17], diagnosis of respiration diseases [18], mental stress and affect recognition [19], [20], monitoring of sleep conditions [21], [22], estimation of blood glucose [23], and drug delivery monitoring [24]-[26] showing its capacity to enhance healthcare systems around the world.

This review explores multi-wavelength PPG approaches for signal acquisition and improved resilience to motion artifacts and variations in skin melanin content and skin temperature with the aim of providing robust estimations of

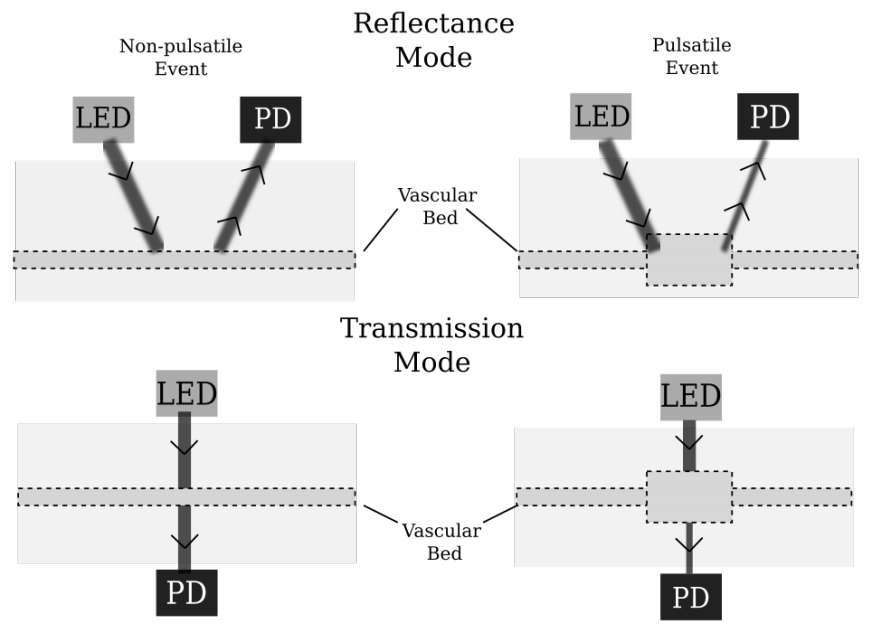

Fig. 2: The two modes of PPG sensing.

physiological parameters. In terms of methodology, the papers which constitute this review were retrieved from the following search engines and digital libraries: Institute of Electrical and Electronics Engineers (IEEE) Xplore Digital Library, Google Scholar, Medline, ScienceDirect, and Wiley Online Library using the keywords: "Multi-wavelength", "Photoplethysmography", "PPG", "Skin Tone", "Skin Temperature", "Skin Optics", "Motion Artifacts", "Physiological Monitoring", "Blood Oxygen Saturation", "Pulse Oximetry", "Blood Pressure", "Blood Glucose" and "Drug Delivery Monitoring".

\section{SKIN OPTICS AND PPG SENSING}

Human skin is a complex heterogeneous medium consisting of three main layers: epidermis, dermis and hypodermis (or subcutaneous tissue), each with varying thicknesses dependent on body site that follow a general trend [27], [28]. The epidermis is the top-most layer of skin comprising of several sub-layers of living and non-living cells, all of which contain little or no blood flow. The stratum corneum or non-living 
epidermis is typically $20 \mu \mathrm{m}$ thick and consists of only dead squamous cells [28]. Beneath is the living epidermis which is typically $100 \mu \mathrm{m}$ thick and contains most of the skin pigmentation compounds, such as pheomelanin and eumelanin, broadly referred to as melanin [27]-[30].

The dermis is found below the epidermis and consists of two main layers: the papillary dermis typically $150 \mu \mathrm{m}$ thick and the reticular dermis which has a thickness generally ranging from $1-4 \mathrm{~mm}$ dependent on body site [28]. The papillary dermis is made up of loose connective tissue which is vascularized from a network of capillaries, small blood vessels typically ranging from $1-8 \mu \mathrm{m}$ in diameter [31] that exchange materials, such as oxygen and carbon dioxide, between blood and tissue. The reticular dermis is made up of dense connective tissue housing structures such as nerves, glands and hair follicles. Additionally, the reticular dermis contains arterioles and venules which are slightly larger blood vessels, typically ranging from 2$30 \mu \mathrm{m}$ in diameter [31], that connect the capillaries to the arteries and veins [27].

The deepest layer of the skin is the hypodermis which connects the skin to the bones and muscles and has a typical thickness in the range of $1-6 \mathrm{~mm}$ dependent on body site [28]. The hypodermis contains larger blood vessels, arteries and veins, typically ranging from $500-5000 \mu \mathrm{m}$ in diameter [31], which transport blood around the body. The hypodermis is mainly used to store fat and primarily consists of loose connective tissue [27].

Due to the inhomogeneous distribution of blood, cells and pigments in the skin; measuring the optical properties is challenging. Usually, the main optical properties of skin are described as absorption, scattering and penetration depth as well as reflection, transmission and fluorescence [6], [28], [29], [32]-[36]. Researchers have employed several methods to model the optical properties of skin such as the radiative transport equation, the Beer-Lambert law, stochastic models such as the Monte Carlo and random walk as well as the adding doubling method with varying results [35], [37]. Summarized in Figure 3 are the wavelengths of light explored in this section and subsequent sections.

\section{A. Optical Properties of Skin and Blood}

The main light-absorbing components within the skin are water, hemoglobin and melanin; however, each absorb light differently depending on the wavelength of light and chemical bonding (Figure 4). Water, the main component of skin, is highly absorbent to IR light (900-1100nm) whilst possessing little to no absorbent qualities to visible light (390-780nm) [6], [28], [34], [36], [38]. Melanin protects the skin against the harmful ultraviolet (UV) radiation from the sun [29], its absorbing qualities increase as the wavelength of light decreases, being highly absorbent to shorter wavelengths ranging from UV to yellow light (200-600nm) [3], [6], [28]-[30], [32][34]. Similarly, hemoglobin's absorbing qualities decrease as the wavelength of light increases. However, when chemically bonded with oxygen, its absorbing qualities dramatically decrease when exposed to light in the range of 570-700nm and is more absorbent to longer wavelengths such as IR when compared to non-oxygenated hemoglobin [6], [28], [29], [32][34], [36], [38].

Scattering occurs as either a surface effect such as reflection and refraction or as an interaction with compounds in the skin that possess different optical properties. It has been estimated that $4-7 \%$ of light is reflected from the surface of the skin independent of wavelength [32]. Generally, within the skin the scattering coefficients decrease with an increase in the wavelength of light [28], [32], [33], [35], [36]. In the epidermis, large melanosomes exhibit mainly forward scattering whilst small "melanin dust" has an isotropic scattering profile. Collagen's fibrous structures define the scattering profile of the dermis whilst the main source of scattering in the hypodermis are spherical droplets of lipids [28]. Additionally, research suggests that the effects of scattering are greater on the breast, abdomen and forehead compared to the arm [36].

The path of light in the skin for reflectance mode PPG sensing is theorized to follow a "banana-like" shape [39] where the maximum depth of the path of light in the skin is called the penetration depth which is a function of its absorption and scattering coefficients [35]. In transmission mode PPG sensing, the path of light travels through the skin from the LED to the photodiode. Generally, the penetration depth for reflectance mode sensing increases as the wavelength of light increases in the range of visible and near-IR light (Figure 5) [3], [6], [28], [33], [34], [36], [38], [40]-[42] with the maximal penetration depth being $3-4 \mathrm{~mm}$ for IR light (800$1100 \mathrm{~nm})$ [28], [36], [42], [43]. When the wavelength of light increases past $1250-1400 \mathrm{~nm}$ the penetration depth significantly decreases [28], [36], [43]. Additionally, the penetration depth of light for reflectance mode sensing changes depending on the measurement site with the breast and abdomen possessing the largest penetration depths compared to the arm and forehead [36].

\section{B. Effects of Biological Characteristics on PPG Sensing}

As described in Section II(A), wavelengths of light interact with skin and blood to varying degrees due to their inhomogeneous nature. Researchers have explored the effects that different biological and skin characteristics have on PPG sensing, which is summarized in this section.

1) Skin Melanin Content: The accuracy and reliability of PPG sensing is sensitive to skin melanin content. First reports of potential inaccuracies arose from pulse oximetry studies which concluded that higher skin melanin content may influence the performance and accuracy [44]. Measurements of pulse oximetry on patients with higher skin melanin content and low blood oxygen saturation had up to $10 \%$ differences in estimates from different pulse oximeters [45] and blood oxygen saturation levels were over-estimated during hypoxia for patients with higher skin melanin content [46]. A larger scale study (1609 subjects: 1333 white patients and 276 black patients) also found black patients to have nearly three times the frequency of occult hypoxemia (an arterial oxygen saturation estimate of $<88 \%$ despite an oxygen saturation of $92 \%$ 96\%) as white patients [47]. However, several other studies suggest that higher skin melanin content doesn't influence 


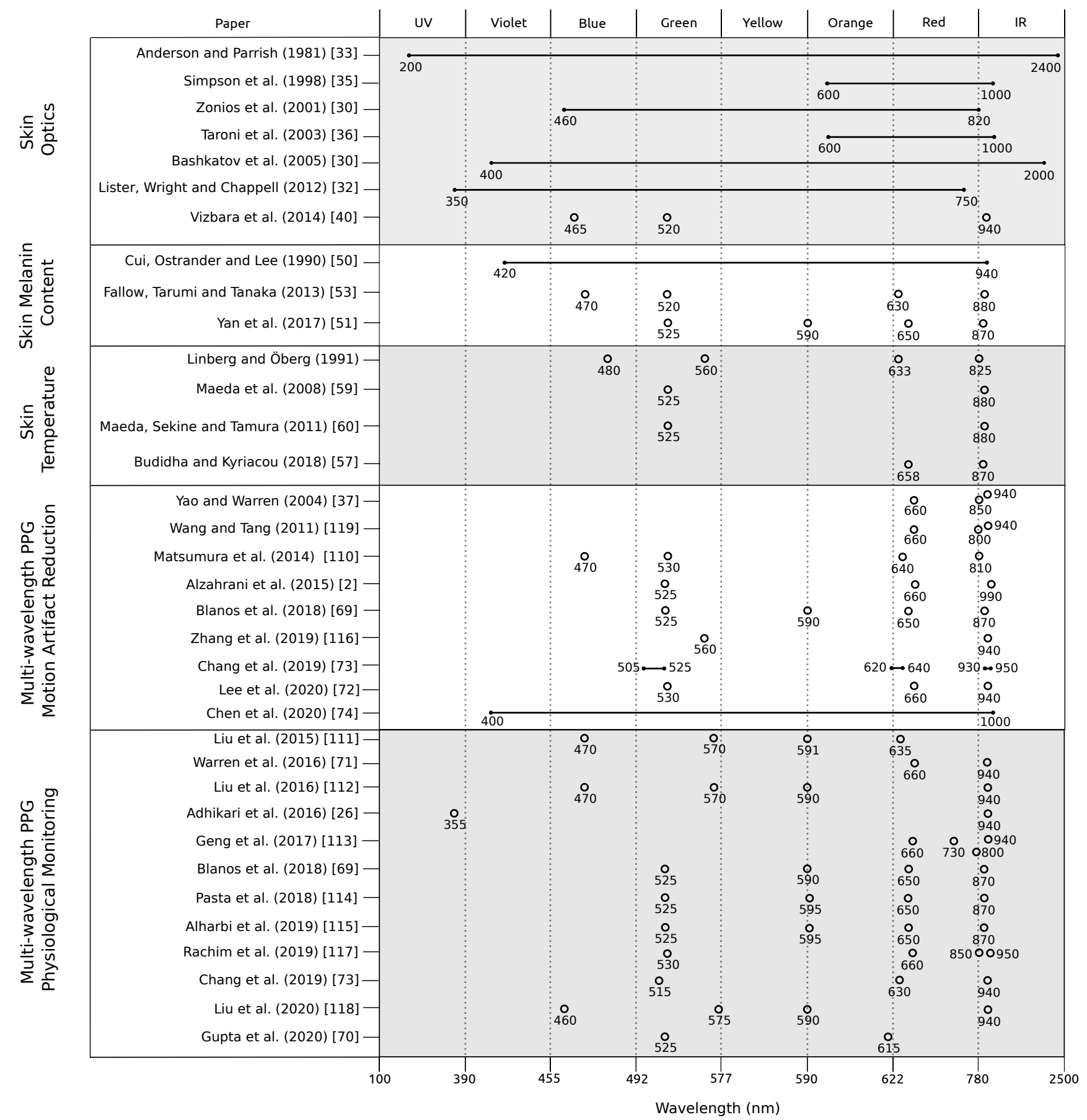

Fig. 3: A summary of the wavelengths of light explored for each multi-wavelength PPG study in each section of this review.

oximetry measurements [48], [49]. Most studies exploring higher skin melanin content and PPG sensing agree that melanin isn't a significant factor when at rest [48], [50]-[52]. The pulsatile component of the PPG signal is collected from the dermis and hypodermis. The epidermis, which contains melanin, absorbs a constant fraction of the signal without affecting the pulsatile component suggesting skin melanin content can be compensated by stronger intensity of light [50], [53]. During active states Bent et al. found no statistically significant differences in HR estimation accuracy across skin tones for commercially available wrist-worn reflectance mode
PPG devices [52]. Fallow et al. found no significant interaction between skin tone and motion type for wrist-worn reflectance mode PPG sensing but did find a trend towards skin type having a significant effect yet no interaction was present at rest [53]. Yan et al. found skin melanin content to not have a significant factor on palm-worn reflectance mode PPG HR estimations as well as green light $(525 \mathrm{~nm})$ producing the best modulation for all skin tones [51]. This agrees with Fallow et al. who found green light $(520 \mathrm{~nm})$ to produce the best modulation for all skin tones at rest although blue $(470 \mathrm{~nm})$ and green $(520 \mathrm{~nm})$ light produced the best modulation for all skin 


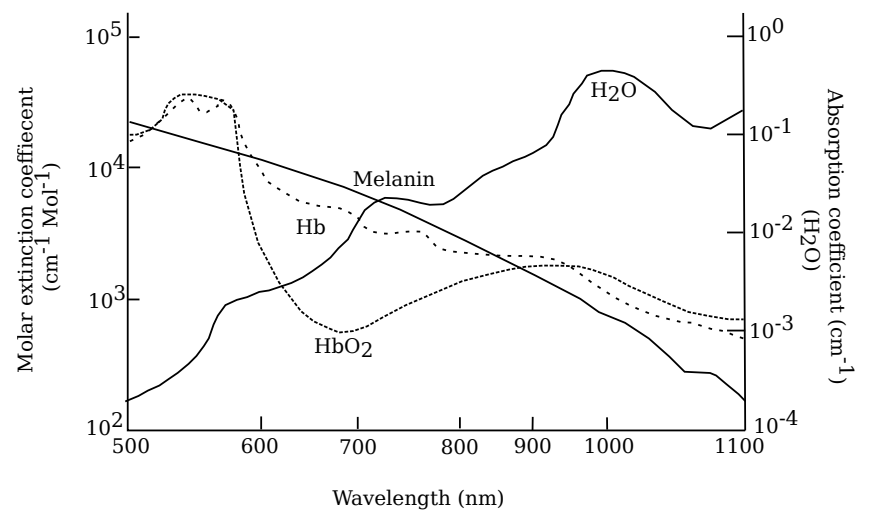

Fig. 4: The light absorption coefficients of biological compounds present in the epidermis-hypodermis layers of skin adapted from Lemay et al. [34].

tones during active state [53]. In contrast, Shcherbina et al. found co-variates such as higher skin melanin content, larger wrist circumference, and higher BMI to positively correlate with increased HR error rates across multiple wrist-worn reflectance mode PPG devices [54]. Additionally, Preejith et al. using a green light reflectance mode wrist-worn PPG sensor on 256 subjects found an mean absolute error of 1.04BPM for lighter skin tones compared to 10.90BPM for darker skin tones when computing HR estimations [55].

2) Skin Temperature: When the temperature of skin reduces, perfusion rates in the vascular bed dramatically decrease due to the Autonomic Nervous System constricting blood vessels in the dermis as a means to conserve body heat [56], [57]. Reductions in skin temperature typically affect the peripheral circulation more than the central areas of the body; for example, when the body is exposed to $10^{\circ} \mathrm{C}$ ambient temperature the blood flow through the hand drops to less than $1 \mathrm{ml} / \mathrm{min}$ [57].

All studies exploring temperature and PPG sensing agree that temperature influences the signal [38], [56]-[61] but to differing degrees. Ralston et al. suggested that errors resulting from varying skin temperatures are unlikely to be clinically significant for transmission mode PPG sensing [58]. However, Budidha et al. found that in some volunteers exposed to cold temperatures, the amplitude of the PPG signal significantly diminished to the extent of being unusable for ear-worn reflectance mode PPG sensing [57].

Maeda et al. found green light $(525 \mathrm{~nm})$ reflectance mode PPG HR estimations to have a higher correlation to the ECG signal HR estimation than IR light $(880 \mathrm{~nm})$ reflectance mode PPG HR estimations at temperatures below $15^{\circ} \mathrm{C}$. As shorter wavelengths penetrate the skin to a lesser degree than longer wavelength they aren't subject to the optical processes that occur in deeper tissue which produce more complex signals. Green PPG signals include less information from various nonpulsatile media therefore affected by noise to a lesser degree than IR PPG signals [59]. In a subsequent study, Maeda et al. found that with cold exposure, the pulsatile component of both green and IR reflectance mode signals decreased significantly whilst the non-pulsatile component remained similar. With hot exposure, the pulsatile component of both green and IR signals as well as the non-pulsatile component the IR signals decreased. The decrease in amplitudes of both components of the IR signal during hot exposure is due to a larger amount of blood in the peripheral vascular bed [60].

3) Other Biological Factors: Although not examined with multi-wavelength PPG devices, there are several other known biological factors that affect PPG sensing. Higher body mass index (BMI) and obesity has been shown to produce less accurate HR estimations [54], [62], [63], which has been speculated to be a co-variate with larger wrist circumferences [64], however other studies reported BMI not to be an affecting factor [65], [66]. Shcherbina et al. also found sex to be an affecting factor with males getting higher error rates [54]. Additionally, Fine et al. explored several studies looking into subject age. As aging leads to various anatomical and physiological changes, the ability of PPG sensing to assess cardiovascular health varies [63].

Other research has suggested that sweat and hair follicle density may be adverse factors to PPG sensing [67] as well as research showing that in underwater conditions skin temperature significantly affects PPG sensing compared to dry conditions [61]. Finally, pre-existing conditions such as Raynaud's syndrome and Anemia may be affecting factors to the accuracy of PPG sensing.

\section{Hardware and Data Collection}

In this section, an examination of the current state-of-theart research and commercial multi-wavelength PPG hardware solutions is given as well as a summary of the various data collection protocols that explored the use of multi-wavelength PPG devices.

\section{A. Multi-wavelength PPG Research Hardware}

Developments into multi-wavelength PPG sensing hardware has seen dramatic improvements of the past decade in research settings. Initial hardware was reliant on fiber optics [41], [68] which then progressed into Optical Electronic Patch Sensor (OEPS) development [51], [69] due to its low cost and simple form factor with researchers also exploring earworn, finger-worn, forehead-worn and wrist-worn PPG sensors [57], [70]-[72]. The latest development in hardware for multiwavelength PPG sensing is an on-chip spectrometer approach based on plasmonic filters [73] which has been adapted for an all-wavelength PPG sensing device [74]. Summarized in Table $[$ are various multi-wavelength PPG research hardware solutions.

The measurement site of PPG sensing is a key factor due to the varying qualities of tissue thickness, skin pigmentation, blood distribution in vascular bed and amount of movement present at the measurement site [76]-[81]. Researchers examined 52 measurement sites across the body finding fingers, palm, face, and ears to produce larger amplitudes of the pulsatile component of the signal when compared to other measurement sites [78]. These findings are consistent with other studies [76], [81]. However, when examining the effects of measurement site on motion artifacts it was found that 
TABLE I: Multi-wavelength PPG Research Hardware Solutions

\begin{tabular}{|c|c|c|c|c|}
\hline Paper & $\begin{array}{l}\text { Sensor } \\
\text { Type }\end{array}$ & Study Materials & Wavelengths & Comments \\
\hline $\begin{array}{l}\text { Spigulis et } \\
\text { al. } \quad(2007) \\
{[41]}\end{array}$ & $\begin{array}{l}\text { Finger-worn } \\
\text { Reflectance } \\
\text { Laser } \\
\text { Sensor }\end{array}$ & $\begin{array}{l}\text { Input fiber: } 600 \mu \mathrm{m} \text { silica core Z-Light, } \\
\text { Ltd. Latvia } \\
\text { Round-to-line detection fiber bundle: } \\
7 \mathrm{x} 200 \mu \mathrm{m} \text { silica core fibers Z-Light, } \\
\text { Ltd. Latvia } \\
\text { Spectrometer: AvaSpec 2048-2 } \\
\text { Avantes BV, The Netherlands }\end{array}$ & $\begin{array}{l}\text { Violet: } 405 \mathrm{~nm} \\
\text { Green: } 532 \mathrm{~nm} \\
\text { Red: } 645 \mathrm{~nm} \\
\text { IR: } 807 \mathrm{~nm} \& \\
\text { 1064nm }\end{array}$ & $\begin{array}{l}\text { Provides exact wavelengths of light making it suitable } \\
\text { for clinical applications however it is unsuitable for } \\
\text { continuous monitoring due to a lack of portability and } \\
\text { obtrusive nature. }\end{array}$ \\
\hline $\begin{array}{l}\text { Leier et al. } \\
(2015) \text { [75] }\end{array}$ & $\begin{array}{l}\text { Wrist-worn } \\
\text { Reflectance } \\
\text { LED Sensor }\end{array}$ & $\begin{array}{l}\text { Four independent groups: } \\
\text { comprising of green, red and two infra- } \\
\text { red LED emitters and a photodiode. }\end{array}$ & $\begin{array}{l}\text { Green: } 560 \mathrm{~nm} \\
\text { Red: } 660 \mathrm{~nm} \\
\text { IR: } 880 \mathrm{~nm} \& \\
\text { 940nm }\end{array}$ & $\begin{array}{l}\text { All optical components are positioned on a flexible } \\
\text { circuit board to allow for movement on the wrist. Light } \\
\text { barriers are provided on the photodiodes to prevent light } \\
\text { crossover and skin back-scattering. LEDs and photodi- } \\
\text { odes are in a matrix formation. Sensor is strapped to } \\
\text { wrist to ensure sufficient contact force. It is unsuitable } \\
\text { for continuous monitoring due to a large form factor of } \\
\text { both the sensor and logic board as well as requiring a } \\
\text { wired connection to a computer. }\end{array}$ \\
\hline $\begin{array}{l}\text { Warren et } \\
\text { al. } \quad(2016) \\
{[71]}\end{array}$ & $\begin{array}{l}\text { Forehead- } \\
\text { worn } \\
\text { Reflectance } \\
\text { LED Sensor }\end{array}$ & $\begin{array}{l}\text { Six photodiodes are positioned concen- } \\
\text { trically around two pairs of red and } \\
\text { IR LEDs at an equidistant separation } \\
\text { distance of } 10 \mathrm{~mm} \text { as well as a tri-axial } \\
\text { accelerometer. }\end{array}$ & $\begin{array}{l}\text { Red: } 660 \mathrm{~nm} \\
\text { IR: } 940 \mathrm{~nm}\end{array}$ & $\begin{array}{l}\text { Positioned on the forehead, signals collected are less } \\
\text { susceptible to motion but may become obtrusive and } \\
\text { inconvenient for daily monitoring. As there are } 6 \text { pho- } \\
\text { todiodes the total active area is } 15.9 \mathrm{~mm}^{2} \text {. An opaque } \\
\text { ring was incorporated to minimize light crossover from } \\
\text { LEDs and photodiodes. }\end{array}$ \\
\hline $\begin{array}{l}\text { Blanos et al. } \\
\text { (2018) [69] }\end{array}$ & $\begin{array}{l}\text { Reflectance } \\
\text { LED OEPS }\end{array}$ & $\begin{array}{l}\text { PPG Sensor: } 4 \text { channel board DISCO4, } \\
\text { Dialog Devices Ltd., Reading, Berk- } \\
\text { shire, UK }\end{array}$ & $\begin{array}{l}\text { Green: } 525 \mathrm{~nm} \\
\text { Orange: } \\
\text { 590nm } \\
\text { Red: } 650 \mathrm{~nm} \\
\text { IR: } 870 \mathrm{~nm}\end{array}$ & $\begin{array}{l}\text { Sensor has a small form factor with LEDs and photo- } \\
\text { diodes in a cross formation with the photodiode in the } \\
\text { center. A layer of clear epoxy medical adhesive was } \\
\text { used to protect the optical components. Patch sensors } \\
\text { can be placed anywhere on the body however due to } \\
\text { perspiration and general wear and tear it requires re- } \\
\text { application making it of a disposable nature. }\end{array}$ \\
\hline $\begin{array}{l}\text { Budidha et } \\
\text { al. } \quad(2018) \\
{[57]}\end{array}$ & $\begin{array}{l}\text { Ear-worn } \\
\text { Reflectance } \\
\text { LED Sensor }\end{array}$ & $\begin{array}{l}\text { LED: CR } 50 \text { IRH and CR } 501 \mathrm{M} \text {, } \\
\text { Excelitas technologies, Massachusetts, } \\
\text { USA } \\
\text { Photodiode: SR } 10 \text { BP-BH, Excelitas } \\
\text { technologies, Massachusetts, USA }\end{array}$ & $\begin{array}{l}\text { Red: } 658 \mathrm{~nm} \\
\text { IR: } 870 \mathrm{~nm}\end{array}$ & $\begin{array}{l}\text { Ear-worn sensor has a small form factor with LEDs } \\
\text { and photodiodes positioned next to each other. Ear- } \\
\text { worn sensors are less susceptible to motion artifacts } \\
\text { and are well suited to remote monitoring during specific } \\
\text { activities. For } 24 \text { hour continuous monitoring ear worn } \\
\text { sensors may become obtrusive and inconvenient. }\end{array}$ \\
\hline $\begin{array}{l}\text { Han et al. } \\
(2019) \text { [42] }\end{array}$ & $\begin{array}{l}\text { Reflectance } \\
\text { LED Sensor }\end{array}$ & $\begin{array}{l}\text { PPG Sensor: 2x AFE4404s Texas In- } \\
\text { struments, Inc., Dallas, TX, USA }\end{array}$ & $\begin{array}{l}\text { Blue: } 460 \mathrm{~nm} \\
\text { Green: } 530 \mathrm{~nm} \\
\text { Red: } 660 \mathrm{~nm} \\
\text { IR: } 940 \mathrm{~nm}\end{array}$ & $\begin{array}{l}\text { Sensor is in a circular formation with } 2 \text { layers of LEDs } \\
\text { with the photodiode in the center. The sensor board was } \\
\text { treated with a black coating to prevent light reflection } \\
\text { as well as providing light barriers to prevent light } \\
\text { crossover and skin back-scattering. }\end{array}$ \\
\hline $\begin{array}{l}\text { Chang et al. } \\
\text { (2019) [73] }\end{array}$ & $\begin{array}{l}\text { Finger-worn } \\
\text { Reflectance } \\
\text { LED Sensor }\end{array}$ & $\begin{array}{l}\text { PPG Sensor: based on plasmonic filters } \\
\text { which can be integrated onto a regular } \\
\text { photo detector. }\end{array}$ & $\begin{array}{l}\text { Green: } 515 \mathrm{~nm} \\
\text { Red: } 630 \mathrm{~nm} \\
\text { IR: } 940 \mathrm{~nm}\end{array}$ & $\begin{array}{l}\text { The sensor has a small form factor based on plasmonic } \\
\text { filters, nanoscale structures on metal films. Providing a } \\
\text { unique way to control polarization and wavelength of } \\
\text { light passing through the structures. Fabrication cost of } \\
\text { the plasmonic filters can be as low as a few dollars at } \\
\text { volume. }\end{array}$ \\
\hline $\begin{array}{l}\text { Lee et al. } \\
(2020) \text { [72] }\end{array}$ & $\begin{array}{l}\text { Wrist-Worn } \\
\text { Reflectance } \\
\text { LED Sensor }\end{array}$ & $\begin{array}{l}\text { PPG Sensor: 4X SFH7050 sensors OS- } \\
\text { RAM, Munich, Germany } \\
\text { Motion Sensor: MPU9250, InvenSense, } \\
\text { San Jose, CA, USA }\end{array}$ & $\begin{array}{l}\text { Green: } 530 \mathrm{~nm} \\
\text { Red: } 660 \mathrm{~nm} \\
\text { IR: } 940 \mathrm{~nm}\end{array}$ & $\begin{array}{l}\text { The sensor consists of } 4 \text { integrated PPG sensing units } \\
\text { positioned in a cross formation. Data collected from } \\
\text { the sensor is streamed to a computer via Bluetooth, } \\
\text { allowing for remote continuous monitoring. The sensor } \\
\text { is attached to the wrist using a wrist sweatband which } \\
\text { may not provide optimal contact force. }\end{array}$ \\
\hline $\begin{array}{l}\text { Gupta et al. } \\
\text { (2020) [70] }\end{array}$ & $\begin{array}{l}\text { Finger-worn } \\
\text { Reflectance } \\
\text { and Trans- } \\
\text { mission } \\
\text { mode LED } \\
\text { Sensor }\end{array}$ & $\begin{array}{l}\text { Two LEDs and a photodiode. Device } \\
\text { allows for both transmission and re- } \\
\text { flectance type PPG signals. An Arduino } \\
\text { micro-controller unit is used to control } \\
\text { the whole system. }\end{array}$ & $\begin{array}{l}\text { Green: } 525 \mathrm{~nm} \\
\text { Red: } 615 \mathrm{~nm}\end{array}$ & $\begin{array}{l}\text { Device provides both transmission and reflectance type } \\
\text { PPG sensing. Transmission mode sensing typically re- } \\
\text { quires obtrusive and inconvenient solutions for contin- } \\
\text { uous monitoring due to positioning of device. }\end{array}$ \\
\hline $\begin{array}{l}\text { Chen et al. } \\
(2020) \text { [74] }\end{array}$ & $\begin{array}{l}\text { Wrist-worn } \\
\text { Reflectance } \\
\text { LED Sensor }\end{array}$ & $\begin{array}{l}\text { LEDs: two white LEDs, a green LED } \\
\text { (525nm), and a IR LED (940nm) } \\
\text { Photodiode: chip-scale spectrometer, } \\
\text { NSP32 (nanolambda, Daejeon, Korea) } \\
\text { as well as a micro-controller and a Blue- } \\
\text { tooth Low Energy transceiver. }\end{array}$ & $\begin{array}{l}\text { All } \\
\text { Wavelength: } \\
400-1000 \mathrm{~nm}\end{array}$ & $\begin{array}{l}\text { The sensor has a small form factor based on plasmonic } \\
\text { filters, nanoscale structures on metal films. Providing a } \\
\text { unique way to control polarization and wavelength of } \\
\text { light passing through the structures with a broad band } \\
\text { of wavelengths that can be utilized. Fabrication cost of } \\
\text { the plasmonic filters can be as low as a few dollars at } \\
\text { volume. }\end{array}$ \\
\hline
\end{tabular}




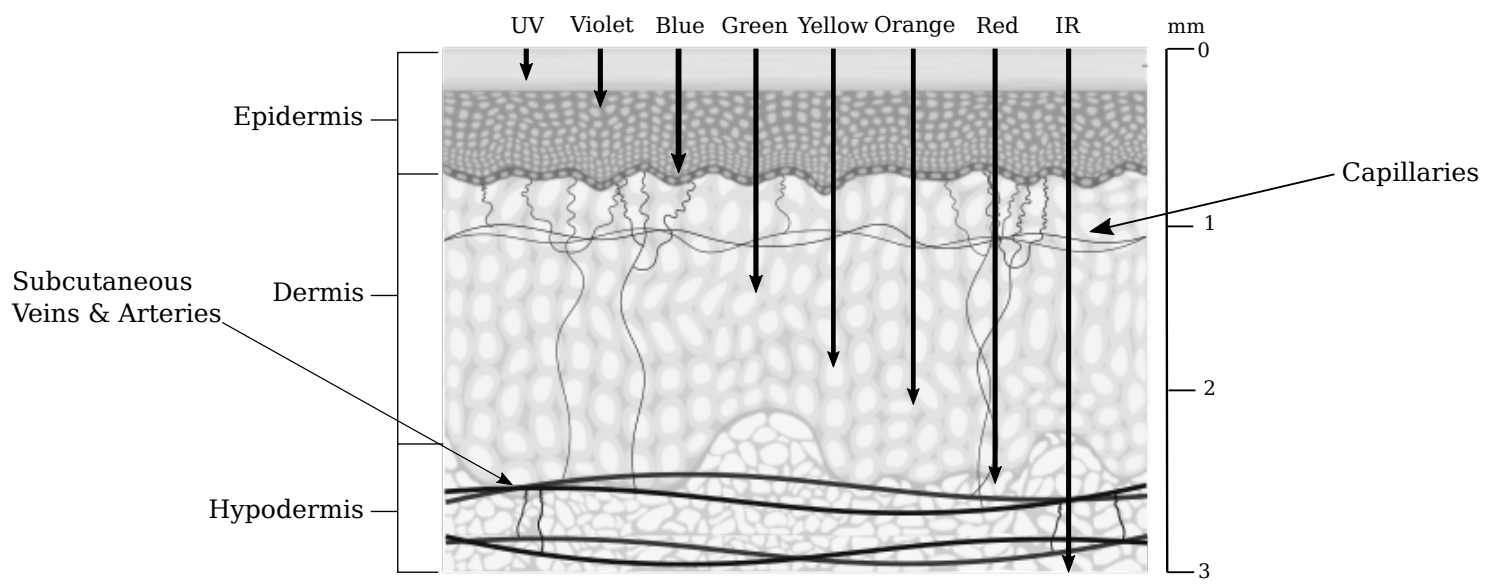

Fig. 5: Approximate maximum penetration depth of each wavelength of light in the skin using reflectance mode sensing.

motion had a large effect on the distribution of blood in the vascular bed at peripheral measurement sites such as fingers and wrist [76], [79].

Due to the preexisting widespread adoption of wrist-worn devices and their unobtrusive nature, the wrist is the most common measurement site for consumer-grade PPG sensing devices. Research shows that the wrist is the worst performing measurement site for extracting HR, pulse oximetry and respiration rate in periods of both rest and movement [81] highlighting the need for more robust methodology. Additionally, researchers have challenged the typical measurement site for wrist-worn PPG sensing device, suggesting the radial zone, side of wrist with the thumb, may produce better signals dependent on light wavelengths selected when compared to the central zone of the dorsal surface of the wrist [82], [83].

\section{B. Multi-wavelength PPG Commercial Hardware}

Polar Unite, Grit X and Vantage V2 are the only devices that currently use four wavelengths [84] whilst the other commercial devices have at most three; typically using green light for HR measurements and red and IR light for pulse oximetry measurements. "Research-grade" multi-wavelength wrist-worn PPG devices such as Empatica E4 and Biovotion Everion (now Biofourmis Biovitals) have the advantage of providing data-streamed raw signals, however, their HR estimation accuracy has been reported to be lower than consumergrade wrist-worn PPG devices with Empatica E4 achieving a mean absolute error of 11.3BPM at rest and 12.8BPM during activity. Biovotion Everion achieved a mean absolute error of $16.5 \mathrm{BPM}$ at rest and 19.8BPM during activity whilst the Apple Watch achieved a mean absolute error of 4.4BPM at rest and 4.6BPM during activity [52]. This is in agreement with Rukasha et al. who found Empatica E4 heart rate estimate mean absolute percentage errors (MAPEs) between $7.2 \%$ and $29.2 \%$ whilst collecting data on a treadmill and heart rate estimate MAPEs between 5.3\% and 13.5\% during 12-hour continuous monitoring [85].

Concerns have arisen due to both consumer and researchgrade devices being used in clinical trials, with Fitbit alone having 476 published studies and 449 studies registered on
ClinicalTrials.gov [86] as well as Apple Watch having gained FDA 510(k) class II clearance for the ECG feature and ability to detect arrhythmias [64] and Empatica Embrace 2 gained FDA 510(k) clearance for epilepsy detection [87]. Fitbit, Garmin and Apple all state that their optical heart rate monitors should not be used as medical devices with intent to diagnose, treat, cure or prevent any disease [88]-[90].

\section{Multi-wavelength PPG Sensing Units and Configurations}

When creating multi-wavelength PPG devices, there are several design choices to be considered such as the number of and placement of LEDs and photo-detectors (PD), intensity of light from LEDs, sample rate, contact force and ambient light and electrical noise cancellation. Summarized in Table II are various multi-wavelength integrated PPG sensors that have been developed and optimized to eliminate having to make the design choices previously mentioned, however they lack the customizability and adaptability required for specific research cases. Analog Front Ends provide a means to develop a custom sensor module adapted to specific needs; a brief summary of multi-wavelength PPG Analog Front Ends is shown in Table III.

In order to develop a sensing unit with an Analog Front End that obtains a strong signal the correct placement of LEDs and PDs is necessary. Research suggests, to obtain the maximum AC/DC ratio, shorter wavelength LEDs such as green should be positioned $1.85 \mathrm{~mm}$ from the PD whilst red and IR LEDs should be placed $2.35 \mathrm{~mm}$ and $2.75 \mathrm{~mm}$ from the PD, respectively [98]. At $9.75 \mathrm{~mm}$ between the LED and PD, no pulsatile waveform was observed at any wavelength [42] and it was found that nearly double the driving current was needed to obtain a signal at similar distances apart for both red and IR LEDs [77]. Increasing the applied current and number of LEDs increases the radiation power [42] however much of the radiation power is not captured if the PD active area is small and may not produce any increase in signal amplitude [99]. Increasing the active area of the PD or number of PDs, however, produces a stronger signal with increases in average amplitude of $42 \%$ for wrist-worn red PPG signals and $73 \%$ 
TABLE II: Multi-wavelength PPG Integrated Sensing Units

\begin{tabular}{|c|c|c|c|c|c|}
\hline \multirow[t]{2}{*}{ Device } & \multicolumn{4}{|c|}{ Wavelength of LEDs } & \multirow[t]{2}{*}{ Features } \\
\hline & Blue & Green & Red & IR & \\
\hline $\begin{array}{l}\text { Analog } \\
\text { Devices } \\
\text { ADPD188GG } \\
{[91]}\end{array}$ & & 2 & & & $\begin{array}{l}2 \text { Photodiodes } \\
\mathrm{I}^{2} \mathrm{C} \& \text { SPI } \\
\text { Communication } \\
2 \text { external sensor } \\
\text { inputs } \\
3 \text { LED drivers } \\
\text { Ambient Light } \\
\text { Rejection }\end{array}$ \\
\hline $\begin{array}{l}\text { Analog } \\
\text { Devices } \\
\text { ADPD144RI } \\
{[92]}\end{array}$ & & & 1 & 1 & $\begin{array}{l}\mathrm{I}^{2} \mathrm{C} \text { Communication } \\
\text { external LED } \\
\text { emitters } \\
\text { Ambient Light } \\
\text { Rejection }\end{array}$ \\
\hline $\begin{array}{l}\text { Maxim } \\
\text { Integrated } \\
\text { MAX30101 } \\
{[93]}\end{array}$ & & 1 & 1 & 1 & $\begin{array}{l}\mathrm{I}^{2} \mathrm{C} \text { Communication } \\
\text { Ambient Light } \\
\text { Rejection }\end{array}$ \\
\hline $\begin{array}{l}\text { Maxim } \\
\text { Integrated } \\
\text { MAX86150 } \\
{[94]}\end{array}$ & & & 1 & 1 & $\begin{array}{l}\mathrm{I}^{2} \mathrm{C} \text { Communication } \\
\text { Ambient Light } \\
\text { Rejection } \\
\text { Electrocardiogram }\end{array}$ \\
\hline $\begin{array}{l}\text { Maxim } \\
\text { Integrated } \\
\text { MAX86916 } \\
{[95]}\end{array}$ & 1 & 1 & 1 & 1 & $\begin{array}{l}\mathrm{I}^{2} \mathrm{C} \text { Communication } \\
\text { Ambient Light } \\
\text { Rejection }\end{array}$ \\
\hline $\begin{array}{l}\text { OSRAM SFH } \\
7072 \text { [96] }\end{array}$ & & 2 & 1 & 1 & $\begin{array}{l}\text { Light Barrier to } \\
\text { block optical } \\
\text { cross-talk } \\
\text { Requires Analog } \\
\text { Front End }\end{array}$ \\
\hline $\begin{array}{l}\text { OSRAM SFH } \\
7050 \text { [97] }\end{array}$ & & 1 & 1 & 1 & $\begin{array}{l}\text { Light Barrier to } \\
\text { block optical } \\
\text { cross-talk } \\
\text { Requires Analog } \\
\text { Front End }\end{array}$ \\
\hline
\end{tabular}

for IR. Additionally, increasing the number of PDs is more beneficial than increasing the number of LEDs as it provides reduced power consumption and heat generation [77], [99]. Finally, it is recommended that the wavelengths are collected in order of size, with the longest first, as the pulsatile event first occurs in the deeper blood vessels [42] as well as having a sample rate in the optimal range of $21-64 \mathrm{~Hz}$ as to compress biomedical data and reduce storage needs [100].

A key factor in PPG sensing is contact force [77], [78], [83], [109]. As the contacting force of the sensor increases the amplitude of the pulsatile component of the signal increases until the difference between the external pressure and the intraarterial pressure, called transmural pressure, reaches zero. At this point the amplitude of the pulsatile component of the signal starts to decrease as the external pressure increases until circulation is cut off due to the flattening of the arterial walls [78], [83], [109]. On the wrist, using reflectance mode, it has been suggested that a contact pressure of $80 \mathrm{mmHg}$ produces the highest amplitude for red light [83]. On the upper arm, using reflectance mode, an average contact pressure of $30 \mathrm{mmHg}$ produces the highest amplitude for green and IR light [78]. Finally, it was found that minimal contact pressure was needed on the forehead using reflectance mode [77].
TABLE III: Multi-wavelength PPG Analog Front Ends

\begin{tabular}{|c|c|c|}
\hline Device & Drivers & Features \\
\hline $\begin{array}{l}\text { Analog Devices } \\
\text { ADPD4000/4001 } \\
\text { [101] } \\
\text { ADPD4100/4101 } \\
\text { [102] }\end{array}$ & $\begin{array}{l}8 \text { LED drivers } \\
8 \text { Inputs for PPG, } \\
\text { ECG, EDA, } \\
\text { impedance and } \\
\text { temperature }\end{array}$ & $\begin{array}{l}\mathrm{I}^{2} \mathrm{C} \& \text { SPI } \\
\text { Communication } \\
\text { Ambient Light } \\
\text { Rejection }\end{array}$ \\
\hline $\begin{array}{l}\text { Maxim Integrated } \\
\text { MAX30110 [103] }\end{array}$ & $\begin{array}{l}2 \text { LED } \\
1 \text { Photodiode }\end{array}$ & $\begin{array}{l}\text { SPI Communication } \\
\text { Ambient Light } \\
\text { Rejection }\end{array}$ \\
\hline $\begin{array}{l}\text { Maxim Integrated } \\
\text { MAXM86146 [104] }\end{array}$ & $\begin{array}{l}3 \text { LED } \\
\text { Two Integrated } \\
\text { Photodiode }\end{array}$ & $\begin{array}{l}\text { SPI Communication } \\
\text { Ambient Light } \\
\text { Rejection } \\
\text { Integrated Micro } \\
\text { Controller }\end{array}$ \\
\hline $\begin{array}{l}\text { Texas Instruments } \\
\text { AFE4950 [105] } \\
\text { AFE44S30 [106] }\end{array}$ & $\begin{array}{l}8 \text { LED } \\
4 \text { Photodiode }\end{array}$ & $\begin{array}{l}\text { 1/2/3 Lead ECG } \\
\text { (AFE4950) } \\
\mathrm{I}^{2} \mathrm{C} \& \text { SPI } \\
\text { Communication } \\
\text { Ambient Light } \\
\text { Rejection }\end{array}$ \\
\hline $\begin{array}{l}\text { Texas Instruments } \\
\text { AFE4900 [107] }\end{array}$ & $\begin{array}{l}4 \text { LED } \\
3 \text { Photodiode }\end{array}$ & $\begin{array}{l}\text { 1 Lead ECG } \\
\mathrm{I}^{2} \mathrm{C} \& \text { SPI } \\
\text { Communication } \\
\text { Ambient Light } \\
\text { Rejection }\end{array}$ \\
\hline $\begin{array}{l}\text { Texas Instruments } \\
\text { AFE4404 [108] }\end{array}$ & $\begin{array}{l}3 \text { LED } \\
1 \text { Photodiode }\end{array}$ & $\begin{array}{l}\mathrm{I}^{2} \mathrm{C} \text { Communication } \\
\text { Ambient Light } \\
\text { Rejection }\end{array}$ \\
\hline
\end{tabular}

A summary of multi-wavelength PPG data collection protocols is given in Table IV. There are only three study protocols which account for skin tone when exploring multiwavelength PPG sensing with larger numbers of lighter skin tones. However, there are single-wavelength data collection protocols that account for skin tone such as Bent et al. [52] and Preejith et al. [55] but fall outside of the scope of this paper. Additionally, there are only three protocols which explore skin temperature and multi-wavelength PPG sensing [57], [59], [60].

\section{iV. Multi-wavelength PPG Motion Artifact REDUCTION}

Motion artifacts are one of the main causes of inaccuracies in PPG sensing. Due to the placement of sensors and the varying penetration depths of light wavelengths, motion from the body distorts the PPG signal. Motion artifacts can be classified as either periodic or non-periodic and can possess amplitudes much larger than the pulsatile component of the signal [72], [116]. Blanos et al. showed that green $(525 \mathrm{~nm})$ and orange $(590 \mathrm{~nm})$ light were affected by artifacts from motion to a lesser degree than red light $(650 \mathrm{~nm})$ [69]. Matsumura et al. agreed stating that the signal to noise ratio (SNR) for green $(530 \mathrm{~nm})$ and blue $(470 \mathrm{~nm})$ light was higher than red (640nm) when being subject to various motion types [110]. Shorter wavelengths can result in improved SNRs because their comparatively shorter path lengths and penetration depths make them less susceptible to noise from motion [72]. Shorter wavelengths also suffer from less attenuation from optical processes, such as absorption and scattering, due to their shorter path lengths. Additionally, the shallower penetration 
TABLE IV: Multi-wavelength PPG Data Collection Study Protocols

\begin{tabular}{|c|c|c|c|c|}
\hline Paper & Motivation & Cohort Metrics & Protocol & Wavelengths \\
\hline $\begin{array}{l}\text { Maeda et al. } \\
\text { (2008) [59] }\end{array}$ & $\begin{array}{l}\text { Skin } \\
\text { Temperature }\end{array}$ & $\begin{array}{l}\text { Subjects: } 22 \\
\text { EXP1: } \\
\text { Age: } 22.4 \pm 0.8 \\
\text { Gender: } 8 \mathrm{M} 3 \mathrm{~F} \\
\text { EXP2: } \\
\text { Age: } 23.6 \pm 3.4 \\
\text { Gender: } 8 \mathrm{M} 2 \mathrm{~F}\end{array}$ & $\begin{array}{l}\text { EXP1: } \\
\text { room temperature of } 25^{\circ} \mathrm{C} \\
\text { Rest seated }-5 \text { minutes } \\
\text { Measurement taken } \\
\text { EXP2: } \\
\text { peripheral skin temperature of } 15^{\circ} \mathrm{C} \\
\text { Rest seated }-5 \text { minutes } \\
\text { Measurement taken }\end{array}$ & $\begin{array}{l}\text { Green: } 525 \mathrm{~nm} \\
\text { IR: } 880 \mathrm{~nm}\end{array}$ \\
\hline $\begin{array}{l}\text { Maeda, Sekine } \\
\text { and Tamura } \\
(2011)[60]\end{array}$ & $\begin{array}{l}\text { Skin } \\
\text { Temperature }\end{array}$ & $\begin{array}{l}\text { Subjects: } 12 \\
\text { Age: } 23.6 \pm 1.5\end{array}$ & $\begin{array}{l}\text { Seated } \\
\text { Cold exposure: Immersed the hand into the isothermal bath } \\
\text { at } 10^{\circ} \mathrm{C} \\
\text { Steady-state reached in } 23.8 \pm 8.2 \text { minutes } \\
\text { Measurements }-1 \text { minute } \\
\text { Hot exposure: Immersed the hand into the isothermal bath } \\
\text { at } 45^{\circ} \mathrm{C} \\
\text { Steady-state reached in } 20.7 \pm 7.3 \text { minutes } \\
\text { Measurements - } 1 \text { minute }\end{array}$ & $\begin{array}{l}\text { Green: } 525 \mathrm{~nm} \\
\text { IR: } 880 \mathrm{~nm}\end{array}$ \\
\hline $\begin{array}{l}\text { Fallow et al. } \\
\text { (2013) [53] }\end{array}$ & Skin Tone & $\begin{array}{l}\text { Subjects: } 23 \\
\text { Age: } 31 \pm 12 \\
\text { Gender: } 11 \mathrm{M} 12 \mathrm{~F} \\
\text { Height: } 172 \pm 8 \mathrm{~cm} \\
\text { Weight: } 72 \pm 14 \mathrm{~kg} \\
\text { Skin Type: I \& II = } \\
8, \text { III }=5, \mathrm{IV}=4, \mathrm{~V} \\
=6\end{array}$ & $\begin{array}{l}\text { Resting forearms } \\
\text { Bicep Curl Flexion - 10s } \\
\text { Grasping Dynamometer with force 5-10nm - 10s }\end{array}$ & $\begin{array}{l}\text { Blue: } 470 \mathrm{~nm} \\
\text { Green: } 520 \mathrm{~nm} \\
\text { Red: } 630 \mathrm{~nm} \\
\text { IR: } 880 \mathrm{~nm}\end{array}$ \\
\hline $\begin{array}{l}\text { Matsumura } \\
\text { et al. (2014) } \\
{[110]}\end{array}$ & $\begin{array}{l}\text { Motion } \\
\text { Artifacts }\end{array}$ & $\begin{array}{l}\text { Subjects: } 12 \\
\text { Age: } 20.6 \pm 0.76 \\
\text { Gender: } 12 \mathrm{M}\end{array}$ & $\begin{array}{l}\text { Adaptation period }-5 \text { minutes } \\
\text { Experimental period: Horizontal motion }-20 \mathrm{~s} \text {, Rest }-10 \mathrm{~s} \text {, } \\
\text { Vertical motion }-20 \mathrm{~s} \text {, Rest }-10 \mathrm{~s} \\
\text { Baseline }-20 \mathrm{~s} \text {, Horizontal motion }-20 \mathrm{~s} \text {, Rest }-10 \mathrm{~s} \text {, Vertical } \\
\text { motion }-20 \mathrm{~s} \text {, Rest }-10 \mathrm{~s} \text {, Baseline }-20 \mathrm{~s}\end{array}$ & $\begin{array}{l}\text { Blue: } 470 \mathrm{~nm} \\
\text { Green: } 530 \mathrm{~nm} \\
\text { Red: } 640 \mathrm{~nm} \\
\text { IR: } 810 \mathrm{~nm}\end{array}$ \\
\hline $\begin{array}{l}\text { Liu et al. } \\
(2015)[111]\end{array}$ & $\begin{array}{l}\text { Physiological } \\
\text { Monitoring }\end{array}$ & $\begin{array}{l}\text { Subjects: } 10 \\
\text { Age: } 22-60 \\
\text { Gender: } 6 \mathrm{M} 4 \mathrm{~F}\end{array}$ & $\begin{array}{l}\text { Rest }-1 \text { minutes } \\
\text { Eight levels of cuff pressure: } 0 \mathrm{mmHg}-15 \mathrm{~s}, 20 \mathrm{mmHg}- \\
15 \mathrm{~s}, 40 \mathrm{mmHg}-15 \mathrm{~s} \text {, Diastolic } \mathrm{BP}(\mathrm{DBP})-15 \mathrm{~s}, \mathrm{DBP}+25 \% \\
-15 \mathrm{~s}, \mathrm{DBP}+50 \%-15 \mathrm{~s}, \mathrm{DBP}+75 \%-15 \mathrm{~s}, \mathrm{DBP}+100 \%-15 \mathrm{~s} \\
\text { Deflated in the reverse order } \\
\text { Rest }-1 \text { minute }\end{array}$ & $\begin{array}{l}\text { Blue: } 470 \mathrm{~nm} \\
\text { Green: } 570 \mathrm{~nm} \\
\text { Orange: } 591 \mathrm{~nm} \\
\text { Red: } 635 \mathrm{~nm}\end{array}$ \\
\hline $\begin{array}{l}\text { Alzahrani et al. } \\
\text { (2015) [2] }\end{array}$ & $\begin{array}{l}\text { Motion } \\
\text { Artifacts }\end{array}$ & $\begin{array}{l}\text { Subjects: } 16 \\
\text { Age: } 20-47 \\
\text { Gender: } 15 \mathrm{M} 1 \mathrm{~F}\end{array}$ & $\begin{array}{l}\text { Standing (30s), Sitting (30s), Walking - 3.0km/h (30s), Walk- } \\
\text { ing }-6.0 \mathrm{~km} / \mathrm{h}(30 \mathrm{~s}), \text { Cycling }-20.0 \mathrm{~km} / \mathrm{h}(60 \mathrm{~s}) \text {, Cycling - } \\
35.0 \mathrm{~km} / \mathrm{h}(60 \mathrm{~s}), \text { Running }-7.0 \mathrm{~km} / \mathrm{h}(30 \mathrm{~s}), \text { Running }-8.5 \mathrm{~km} / \mathrm{h} \\
(30 \mathrm{~s})\end{array}$ & $\begin{array}{l}\text { Green: } 525 \mathrm{~nm} \\
\text { Red: } 660 \mathrm{~nm} \\
\text { IR: } 990 \mathrm{~nm}\end{array}$ \\
\hline $\begin{array}{l}\text { Liu et al. } \\
\text { (2016) [112] }\end{array}$ & $\begin{array}{l}\text { Physiological } \\
\text { Monitoring }\end{array}$ & $\begin{array}{l}\text { Subjects: } 20 \quad(10 \\
\text { Healthy/10 Patients } \\
\text { with Cardiovascular } \\
\text { diseases }(\text { CVD })) \\
\text { Average Healthy } \\
\text { Age: } 26 \quad \\
\text { Average CVD Age: } \\
68\end{array}$ & $\begin{array}{l}\text { Subjects at rest in seated position } \\
\text { Reference BP was measured on the middle finger and left } \\
\text { upper arm. One-lead ECG electrodes on the left and right } \\
\text { arms of the subjects. A custom made four-wavelength PPG } \\
\text { device used to collect PPG signals }\end{array}$ & $\begin{array}{l}\text { Blue: } 470 \mathrm{~nm} \\
\text { Green: } 570 \mathrm{~nm} \\
\text { Yellow: } 590 \mathrm{~nm} \\
\text { IR: } 940 \mathrm{~nm}\end{array}$ \\
\hline $\begin{array}{l}\text { Warren et al. } \\
\text { (2016) [71] }\end{array}$ & $\begin{array}{l}\text { Motion } \\
\text { Artifacts \& } \\
\text { Physiological } \\
\text { Monitoring }\end{array}$ & $\begin{array}{l}\text { Subjects: } 15 \\
\text { Age: } 23-30\end{array}$ & $\begin{array}{l}\text { Alternate between } 3 \mathrm{~min} \text { of rest and } 5 \mathrm{~min} \text { of bouncing on a } \\
\text { exercise ball for a total of } 19 \text { min. Using a reference device } \\
\text { Masimo-57 Radical (Masimo SET@, Masimo Corporation, } \\
\text { CA, USA) finger type transmittance pulse oximeter that was } \\
\text { kept motionless by resting the left hand on a table. }\end{array}$ & $\begin{array}{l}\text { Red: } 660 \mathrm{~nm} \\
\text { IR: } 940 \mathrm{~nm}\end{array}$ \\
\hline $\begin{array}{l}\text { Adhikari et al. } \\
\text { (2016) [26] }\end{array}$ & $\begin{array}{l}\text { Physiological } \\
\text { Monitoring }\end{array}$ & Subjects: $5 / 3 / 3$ Mice & $\begin{array}{l}\text { A delivered dose was } 5 \mathrm{mg} / \mathrm{kg} \text {, which is the typical clinical } \\
\text { dose. The PPG device is placed on the tail throughout the in- } \\
\text { jection phase, then for short periods throughout the clearance } \\
\text { phase. } 6 \text { samples for gold nanorods, } 9 \text { samples for quinine } \\
\text { and } 7-8 \text { samples for amphotericin B }\end{array}$ & $\begin{array}{l}\text { UV: } 355 \mathrm{~nm} \\
\text { IR: } 805 \mathrm{~nm}\end{array}$ \\
\hline $\begin{array}{l}\text { Yan et al. } \\
(2017)[51]\end{array}$ & Skin Tone & $\begin{array}{l}\text { Subjects: } 33 \\
\text { Age: } 18-41 \\
\text { Gender: } 33 \mathrm{M} \\
\text { Skin Type: I \& II = } \\
11, \mathrm{III}=10, \mathrm{IV}=7 \text {, } \\
\mathrm{V}=5\end{array}$ & $\begin{array}{l}\text { Room temperature: } 23-26^{\circ} \mathrm{C} \text {, Humidity: } 22-36 \% \\
\text { Resting, Walking }(3 \mathrm{~km} / \mathrm{h}) \text {, Jogging }(6 \mathrm{~km} / \mathrm{h}), \text { Running }(9 \mathrm{~km} / \mathrm{h})\end{array}$ & $\begin{array}{l}\text { Green: } 525 \mathrm{~nm} \\
\text { Orange: } 590 \mathrm{~nm} \\
\text { Red: } 650 \mathrm{~nm} \\
\text { IR: } 870 \mathrm{~nm}\end{array}$ \\
\hline $\begin{array}{l}\text { Geng et al. } \\
\text { (2017) [113] }\end{array}$ & $\begin{array}{l}\text { Physiological } \\
\text { Monitoring }\end{array}$ & $\begin{array}{l}\text { Subjects: } 99 \quad(6 \\
\text { Healthy/3 Diabetic) }\end{array}$ & $\begin{array}{l}3 \text { lunch experiments \& } 2 \text { supper experiments. } \\
\text { Lunch was standardized to } 90 \mathrm{~g} \text { of standard tortilla, while the } \\
\text { supper was without specific requirements. } \\
\text { Healthy volunteers did lunch experiment without wearing } \\
\text { the dynamic glucometer. At } 10 \text { min before the meal, finger } \\
\text { stick glucose monitoring (Roche glucometer, ACCU-CHEK® } \\
\text { Performa) was used for reference glucose then performed once } \\
\text { every } 30 \text { mins. }\end{array}$ & $\begin{array}{l}\text { Red: } \\
\text { IR: }\end{array}$ \\
\hline
\end{tabular}


TABLE IV: Multi-wavelength PPG Data Collection Study Protocols

\begin{tabular}{|c|c|c|c|c|}
\hline Paper & Motivation & Cohort Metrics & Protocol & Wavelengths \\
\hline $\begin{array}{l}\text { Budidha and } \\
\text { Kyriacou } \\
\text { (2018) [57] }\end{array}$ & $\begin{array}{l}\text { Skin } \\
\text { Temperature }\end{array}$ & $\begin{array}{l}\text { Subjects: } 15 \\
\text { Age: } 28 \pm 5 \\
\text { Gender: } 9 \mathrm{M} 6 \mathrm{~F}\end{array}$ & $\begin{array}{l}\text { Basline Temperature }\left(24^{\circ} \mathrm{C}\right)-2 \text { minutes, Cold Exposure } \\
\left(10 \pm 1^{\circ} \mathrm{C}\right)-10 \text { minutes, Baseline Temperature }\left(24^{\circ} \mathrm{C}\right)-10 \\
\text { minutes }\end{array}$ & $\begin{array}{l}\text { Red: } 658 \mathrm{~nm} \\
\text { IR: } 870 \mathrm{~nm}\end{array}$ \\
\hline $\begin{array}{l}\text { Blanos et al. } \\
\text { (2018) [69] }\end{array}$ & $\begin{array}{l}\text { Physiological } \\
\text { Monitoring }\end{array}$ & $\begin{array}{l}\text { Subjects: } 15 \\
\text { Age: } 25 \pm 5 \\
\text { Height: } 178.9 \quad \pm \\
4.2 \mathrm{~cm} \\
\text { Weight: } 70.9 \pm 7.9 \mathrm{~kg}\end{array}$ & $\begin{array}{l}\text { Settle - 30s, Rest }-180 \mathrm{~s} \text {, Settle }-30 \mathrm{~s} \text {, Cycling }-180 \mathrm{~s} \text {, Settle } \\
-30 \mathrm{~s}, \text { Run }(3 \mathrm{Km} / \mathrm{h})-180 \mathrm{~s} \text {, Settle }-30 \mathrm{~s} \text {, Run }(6 \mathrm{Km} / \mathrm{h})-180 \mathrm{~s}\end{array}$ & $\begin{array}{l}\text { Green: } 525 \mathrm{~nm} \\
\text { Orange: } 595 \mathrm{~nm} \\
\text { Red: } 650 \mathrm{~nm} \\
\text { IR: } 870 \mathrm{~nm}\end{array}$ \\
\hline $\begin{array}{l}\text { Pasta et al. } \\
\text { (2018) [114] }\end{array}$ & $\begin{array}{l}\text { Physiological } \\
\text { Monitoring }\end{array}$ & $\begin{array}{l}\text { Subjects: } 25 \\
\text { Age: } 28 \pm 7 \\
\text { Skin Tone: } \mathrm{I}=1, \mathrm{II} \\
=9, \mathrm{III}=9, \mathrm{IV}=1, \\
\mathrm{~V}=2 \\
\mathrm{VI}=1\end{array}$ & $\begin{array}{l}\text { OEPS signal was measured at: } \\
\text { Fingertip, Rest }-2 \text { minutes, Radial artery, Rest }-2 \text { minutes, } \\
\text { Wrist, Rest }-2 \text { minutes }\end{array}$ & $\begin{array}{l}\text { Green: } 525 \mathrm{~nm} \\
\text { Orange: } 595 \mathrm{~nm} \\
\text { Red: } 650 \mathrm{~nm} \\
\text { IR: } 870 \mathrm{~nm}\end{array}$ \\
\hline $\begin{array}{l}\text { Alharbi et al. } \\
\text { (2019) [115] }\end{array}$ & $\begin{array}{l}\text { Physiological } \\
\text { Monitoring }\end{array}$ & $\begin{array}{l}\text { Subjects: } 31 \\
\text { Age: } 25 \pm 5 \\
\text { Gender: } 31 \mathrm{M} \\
\text { Height: } 179 \pm 4 \mathrm{~cm}\end{array}$ & $\begin{array}{l}\text { Protocol 1: Sitting with hand movements } \\
\text { Protocol 2: Cycling and Walking }\end{array}$ & $\begin{array}{l}\text { Green: } 525 \mathrm{~nm} \\
\text { Orange: } 595 \mathrm{~nm} \\
\text { Red: } 650 \mathrm{~nm} \\
\text { IR: } 870 \mathrm{~nm}\end{array}$ \\
\hline $\begin{array}{l}\text { Zhang et al. } \\
\text { (2019) [116] }\end{array}$ & $\begin{array}{l}\text { Motion } \\
\text { Artifacts }\end{array}$ & $\begin{array}{l}\text { Subjects: } 6 \\
\text { Age: } 25-35\end{array}$ & $\begin{array}{l}\text { Stationary }-5 \text { minutes } \\
\text { Motion: Index finger tapping, Hand waving (horizontal), } \\
\text { Hand shaking (vertical), } \\
\text { Running arm swing, Fist opening and closing, Radial/ulnar } \\
\text { deviation, } \\
\text { Wrist extension/flexions }\end{array}$ & $\begin{array}{l}\text { Green: } 560 \mathrm{~nm} \\
\text { IR: } 940 \mathrm{~nm}\end{array}$ \\
\hline $\begin{array}{l}\text { Rachim et al. } \\
\text { (2019) [117] }\end{array}$ & $\begin{array}{l}\text { Physiological } \\
\text { Monitoring }\end{array}$ & $\begin{array}{l}\text { Subjects: } 12 \\
\text { Age: } 22-30, \\
\text { Gender: } 2 \mathrm{~F} 4 \mathrm{M}\end{array}$ & $\begin{array}{l}\text { Commercial ECG device AD8232 (Analog Devices Inc., } \\
\text { USA) and PPG device RP520 (Laxtha Inc., Korea) were used } \\
\text { as reference devices. Each subject sat in a chair. Data points } \\
\text { are collected every } 10 \text { min, to find baseline value. After that, } \\
\text { the subject ate a carbohydrate rich meals, then collected data } \\
\text { every } 20 \text { min for a total } 120 \mathrm{~min}\end{array}$ & $\begin{array}{l}\text { Green: } 530 \mathrm{~nm} \\
\text { Red: } 660 \mathrm{~nm} \\
\text { IR: } 850 \& 950 \mathrm{~nm}\end{array}$ \\
\hline $\begin{array}{l}\text { Chang et al. } \\
\text { (2019) [73] }\end{array}$ & $\begin{array}{l}\text { Motion } \\
\text { Artifacts \& } \\
\text { Physiological } \\
\text { Monitoring }\end{array}$ & $\begin{array}{l}\text { Subjects: } 10 \\
\text { Age: } 20-60 \\
\text { Gender: } 7 \mathrm{M} 3 \mathrm{~F} \\
\text { Height: } 155-180 \mathrm{~cm}\end{array}$ & $\begin{array}{l}\text { Index finger is placed on the sensing devices } \\
\text { A blood oximetry meter (TRUST, TD-8250A) and an upper } \\
\text { arm blood pressure monitor (Omron, HEM-7121) are used as } \\
\text { reference devices }\end{array}$ & $\begin{array}{l}\text { Green: } 505,510, \\
515,520 \& 525 \mathrm{~nm} \\
\text { Red: } 620,625, \\
\text { 630, } 635 \& 640 \mathrm{~nm} \\
\text { IR: } 930,935,940, \\
945 \& 950 \mathrm{~nm}\end{array}$ \\
\hline $\begin{array}{ll}\text { Lee } & \text { et } \\
(2020) & \text { [72] }\end{array}$ & $\begin{array}{l}\text { Motion } \\
\text { Artifacts }\end{array}$ & $\begin{array}{l}\text { Subjects: } 7 \\
\text { Age: } 27.1 \pm 5\end{array}$ & $\begin{array}{l}\text { Resting }-1 \text { minute, Walking- } 2 \text { minutes }(1 \mathrm{~m} / \mathrm{s}) \text {, Resting - } \\
1 \text { minute, Fast Walking }-2 \text { minutes }(1.8 \mathrm{~m} / \mathrm{s}) \text {, Resting }-1 \\
\text { minute, Running }-2 \text { minutes }(2.2 \mathrm{~m} / \mathrm{s})\end{array}$ & $\begin{array}{l}\text { Green: } 530 \mathrm{~nm} \\
\text { Red: } 660 \mathrm{~nm} \\
\text { IR: } 940 \mathrm{~nm}\end{array}$ \\
\hline $\begin{array}{l}\text { Liu et al. } \\
(2020)[118]\end{array}$ & $\begin{array}{l}\text { Physiological } \\
\text { Monitoring }\end{array}$ & $\begin{array}{l}\text { Subjects: } 22 \\
\text { Age: } 70.2 \pm 5.4 \\
\text { Gender: } 17 \mathrm{M} 5 \mathrm{~F}\end{array}$ & $\begin{array}{l}\text { Rest }-5 \text { minutes } \\
\text { Measurements taken } \\
\text { Rehabiliation Exercise }-2 \text { hours } \\
\text { lower limb strengthening and balance exercises with mobility } \\
\text { and agility training. } \\
\text { Rest }-5 \text { minutes } \\
\text { Measurements taken }\end{array}$ & $\begin{array}{l}\text { Blue: } 460 \mathrm{~nm} \\
\text { Green: } 575 \mathrm{~nm} \\
\text { Orange: } 590 \mathrm{~nm} \\
\text { IR: } 940 \mathrm{~nm}\end{array}$ \\
\hline $\begin{array}{l}\text { Chen et al. } \\
(2020)[74]\end{array}$ & $\begin{array}{l}\text { Motion } \\
\text { Artifacts }\end{array}$ & Subjects: 6 & $\begin{array}{l}\text { Used the developed device to record the MRC-AW-PPG } \\
\text { signals, and then used AFE4404EVM as a reference to record } \\
\text { the green, red, and NIR PPG signals separately, all in the three } \\
\text { different postures (hands down, hands forward \& hands up) } \\
\text { whilst seated }\end{array}$ & $\begin{array}{l}\text { All Wavelength: } \\
400-1000 \mathrm{~nm}\end{array}$ \\
\hline
\end{tabular}

depths for shorter wavelengths result in less physiological information from deeper tissue such as bone movement being collected [69]. However, some shorter wavelengths due to shallower penetration depths do not reveal much cardiac activity [72]. The typical frequency range of a PPG signal is $0-5 \mathrm{~Hz}$ whilst motion artifacts fall within $0-10 \mathrm{~Hz}$ making the removal of motion artifacts challenging. Most approaches that tackle motion artifacts involve the use of a motion reference signal, typically collected from an accelerometer or gyroscope [116]. Wang et al. used the isobestic $(800 \mathrm{~nm})$ wavelength as a motion reference, implementing a normalized least mean squares adaptive noise canceling algorithm to reconstruct the clean PPG signal [119]. Zhang et al. proposed a similar method using an infrared (940nm) PPG signal as a motion reference, due to its comparatively deep penetration depths and susceptibility to motion implementing a continuous wavelet transform for signal cleaning and reconstruction reducing error in HR estimations for all motion types to less than 2BPM [116]. Yao et al. developed a method to separate motion artifacts from PPG signals using an algorithm based on the Beer-Lambert law which utilized red $(660 \mathrm{~nm})$ and two infrared $(850$ and $940 \mathrm{~nm})$ wavelengths [37]. The Beer-Lambert law suggests that the sum of transmitted and absorbed or scattered light is equal to the incident light through homogeneous layers however human skin and blood are not homogeneous [34]. Chang et al. used 15 PPG signals and the maximal-ratio combined algorithm 
as a means for motion artifact reduction showing a 50\% variation reduction when compared with the single-wavelength reference sensor [73]. Similarly, Chen et al. used a maximalratio combined algorithm on an all-wavelength wrist-worn PPG device. The results showed the all-wavelength approach had an improved SNR when compared to the conventional green, red and IR PPG sensing [74]. Lee et al. developed a motion artifact reduction algorithm using 12-channel PPG signals comprising of green $(530 \mathrm{~nm})$, red $(660 \mathrm{~nm})$ and IR (940nm) wavelengths. An independent component analysis was first carried out to extract the independent components of the signals. The most pulsatile component of the signals were then selected using principal component analysis implemented with a truncated singular value decomposition showing a sensitivity of $82.49 \%$, a positive predictive value of $99.83 \%$, and a false detection rate of $0.17 \%$ in periods of high motion [72].

\section{Multi-Wavelength PPG Physiological MONITORING}

In this section, an examination of the current state-of-the art research physiological measurement extraction methodologies is given ranging from cardiovascular measurements such as blood oxygen saturation, HR, blood pressure and blood glucose as well as other physiological measurements.

\section{A. Blood Oxygen Saturation \& Heart Rate}

Currently, the most common application for multiwavelength PPG sensing is pulse oximetry as it requires two wavelengths to calculate blood oxygen saturation levels. The blood oxygen saturation level can be estimated from the ratio of pulsatile and non-pulsatile components of each wavelength [9]. Typically, the wavelengths used are red $(622-780 \mathrm{~nm})$ and IR (780-2400nm) [73] however, researchers have identified orange and green light to perform better due to their robustness against motion artifacts [69], [115].

Alharbi et al. found that green-orange pulse oximetry measurements from a reflectance mode OEPS device had a $\mathrm{r}=0.98$ correlation with commercial pulse oximeter in periods of both rest and motion as well as a $r=0.98$ correlation with pulse oximetry measurements from red-IR light using the same OEPS device in periods of both rest and motion [115]. Additionally, Blanos et al. found no significant difference between green-orange pulse oximetry measurements from a reflectance mode OEPS device and a commercial pulse oximeters in periods of both rest and motion [69]. Blanos et al. also extracted HR estimations from a reflectance mode OEPS device at four different wavelengths in both periods of rest and motion. It was found that green light had a correlation of $r=0.992$ with the recorded ECG values. Orange light had a correlation of $\mathrm{r}=0.984$, whilst red and IR light had a correlation of $\mathrm{r}=0.952$ and $\mathrm{r}=0.97$, respectively [69].

Warren et al. developed a multi-channel, multi-wavelength forehead-worn PPG reflectance sensor, using two red (660nm) and two IR $(940 \mathrm{~nm})$ wavelengths, with a tri-axial accelerometer. They also developed an advanced multi-channel switching algorithm that chooses the channel least affected by motion artifacts to calculate HR estimates for each time instant. They found that for a wide variety of random motion, channels respond differently to motion artifacts. The multi-channel switching algorithm estimates produced improved results compared to the individual channel estimates because the multichannel switching algorithm enabled automatic selection of the best signal fidelity channel at each time point among the multi-channel PPG data [71].

Green-orange pulse oximetry has shown to be a promising alternative due to their robustness against motion [69] and should be explored further in daily activity settings. Utilizing two wavelengths for HR estimations showed promising results [71]. Further exploration of methods using multiple wavelengths for HR estimations may uncover improved results.

\section{B. Blood Pressure}

Blood Pressure (BP) can be extracted using an ECG and peripheral PPG sensing to compute the Pulse Transit Time (PTT) which has a high correlation with systolic blood pressure (SBP) and diastolic blood pressure (DBP). Liu et al. developed a reflectance mode multi-wavelength light-skin interaction model based on the modified Beer-Lambert law. The model was calibrated for BP extraction using a cuff-based BP measuring device and ECG. Evaluating the dominance of different pulsation patterns based on absorption weighting factors showed a significantly improved BP tracking ability. The mean absolute difference between the reference and the estimated SBP varies from $5.7 \mathrm{mmHg}$ (for single-wavelength PPG) to $4.0 \mathrm{mmHg}$ (for two-wavelength PPG) and $2.9 \mathrm{mmHg}$ (for three-wavelength PPG) [112]. Blood pressure estimation methods require a cuff-based BP measuring device for calibration. When the cuff is inflated, pressure is exerted on the vascular bed causing the arterial properties to potentially be altered due to the smooth muscle relaxation, thereby increasing the PTT. Liu et al. examined the effect of cuff induced pressure and subsequent effects on the PTT at four different wavelengths of light using reflectance mode: blue $(470 \mathrm{~nm})$, green $(570 \mathrm{~nm})$, yellow $(591 \mathrm{~nm})$ and red $(635 \mathrm{~nm})$. The results showed that red PTT, yellow PTT and green PTT had a trend of increased PTTs after cuff pressurization while blue PTT nearly had no change. Indicating that PTTs calculated from cuff-based BP measuring devices and different wavelengths of PPG are influenced by smooth muscle relaxation to different degrees. Blue light has a relatively shallow penetration depth so blue PTT stays nearly unchanged after cuff pressurization. Yellow PTT had the most significant change which may be due to yellow light having deeper penetration depths into the skin compared to blue light therefore reaching muscle tissue that is influenced by smooth muscle relaxation from the inflated cuff to a greater degree. Additionally, yellow light has shallower penetration depths than red light so is unable to reach the larger blood vessels found in deeper tissue [111].

Efforts have been made to extract BP estimates without ECG devices using the time difference between different wavelengths of PPG signals, referred to as local PTT, due to its strong relationship to PTT showing promising results. Pasta et al. examined BP cuff-based measurements from reflectance 
mode multi-wavelength PPG sensing at 3 different locations (fingertip, radial artery and dorsal surface of wrist) using four different wavelengths (green $525 \mathrm{~nm}$, orange $595 \mathrm{~nm}$, red $650 \mathrm{~nm}$ and IR $870 \mathrm{~nm}$ ) without an ECG device for calibration. When the cuff was pressurized, the blood vessels were gradually blocked by the increasing pressure. As the systolic pressure was reached, the PPG signals became too weak for the sensor to pick it up. Upon the signal's disappearance, the cuff pressure was decompressed gradually. Then, the PPG pulse reappeared at a certain point. The algorithm was able to identify all the peaks and provided information such as the time of signal loss and re-acquisition, thus allowing for a correlation with the pressure inside the cuff. The results showed that the fingertip site provided the most accurate values amongst all wavelengths with an error of $8.07 \%$, compared to the radial artery error of $13.17 \%$ and the wrist error of $17.44 \%$. Green light recorded the best performance for every site, followed by the orange light with an error difference of $2 \%$. Red light obtained the best results on the fingertip, with an error of $6.33 \%$ whilst IR had an error of $7.27 \%$. Additionally, it was reported that smaller error rates were obtained from lighter skin tones compared to darker skin tones [114].

Chang et al. produced a method without an ECG device using 15 different reflectance mode wavelengths extracting local PTT using a cross-correlation method. The average of the 15 local PTTs was computed and used with regression coefficients of the linear models for SBP and DBP to estimate SBP and DBP values with correlations of $r=0.79$ and $r=0.78$, respectively [73]. Liu et al. proposed a method, similarly without an ECG device. Using shorter wavelengths, blue and green, to measure the capillary pulsation and longer wavelengths, red and IR, to measure the arterial pulsation using reflectance mode sensing. Principle component analysis was employed to extract the first principle component of the shorter wavelengths as the capillary pulse and the second principle component as the motion signal as well as the first principle component of the longer wavelengths as the arterial pulse. From these principle components, Fourier transforms are used to extract features such as phase shift which indicates arteriolar PTT and HR with heart period and pulse decay time being computed separately. These features are used to compute mean blood pressure and pulse pressure which are then transformed into SBP and DBP estimates yielding errors of $1.44 \pm 6.89 \mathrm{mmHg}$ for SBP and $-1.00 \pm 6.71 \mathrm{mmHg}$ for DBP [118].

Utilizing multiple wavelengths for BP estimations showed improved error rates compared to single-wavelength estimations [73], [112], [118] especially when taking advantage of the differing interactions of wavelengths with skin and blood [118]. Methods that do not require an ECG device [73], [114], [118] have the advantage of not requiring multiple devices.

\section{Blood Glucose}

As well as Blood Pressure sensing, another application of wearable multi-wavelength PPG sensing is Blood Glucose (BG) estimation. Gupta et al. analyzed the mode of PPG sensing when extracting BG measurements. Two wavelengths of light, green $(525 \mathrm{~nm})$ and red $(615 \mathrm{~nm})$, were collected from the finger using both transmission and reflectance modes of PPG sensing. All collected signals were subject to a 10th order low pass Butterworth filter with a cutoff frequency of $8 \mathrm{~Hz}$. The filtered signals were then used to extract 22 features which can be split into two parts: PPG based and general signal characteristics. The PPG features included $\mathrm{HR}, \mathrm{SpO}_{2}$ and breathing rate whilst the signal characteristics included zero-crossing rate, power spectral density, Teager-Kaiser energy and QiZheng energy. These features were then used in a random forest regression algorithm. In transmission, the correlation between the estimated BG measurements and the reference device was $r=0.72$ pre-prandial (before food consumption) and $\mathrm{r}=0.91$ post-prandial (after food consumption). In reflectance mode, the correlation pre-prandial was $r=0.82$ whilst the correlation post-prandial was $\mathrm{r}=0.62$ [70].

Geng et al. developed a multi-site and multi-sensor system consisting of a wrist-worn device and an upper-arm worn device. The wrist-worn device contained a temperature sensor, a humidity sensor, a high frequency flexible electrode and one pole of a low-frequency electrode as well as a multiwavelength reflectance PPG sensor (red - 660nm and IR - 730nm, 800nm and 940nm). The upper arm device was equipped with the other pole of the low-frequency electrode to detect the low-frequency impedance of the arm. All candidate features were calculated from the original signals and were screened according to the similarity between the feature and reference glucose profile. A single-feature model was constructed based on the candidate features using time series analysis. A weighted average method was used on the single-feature model-based glucose profiles to produce multi-feature fusion parameters. The glucose profile estimation model is made up of both the single-feature model-based glucose profiles and multi-feature fusion parameters. After the estimated glucose profile was obtained, the peak time of postprandial glucose can be obtained. The results show a correlation between the reference device and the estimated values of $\mathrm{r}=0.83$ and a standard error of prediction (SEP) of $14.6 \mathrm{mg} / \mathrm{dL}$ [113].

Rachim et al. analyzed four wavelengths of light (green, red and two IR) in extracting BG measurements from the wrist using reflectance mode sensing. A local maxima algorithm was used to detect the peaks in the collected signals which were then segmented into windows and averaged using an ensemble average algorithm. From the averaged signals, 24 features were extracted: 12 features from the difference of optical density between the pulsatile components and the amplitude of non-pulsatile component as well as 12 features from a Teager-Kaiser energy operator. The features were then used in a Partial Least Squares algorithm to find the relationship between the reference device and extracted features. Using only green $(535 \mathrm{~nm})$ and red light $(660 \mathrm{~nm})$ a SEP of $12.4 \mathrm{mg} / \mathrm{dL}$ was found and a correlation of $r=0.55$ with the reference device. Using only IR light (850nm and 950nm) a SEP of $10.1 \mathrm{mg} / \mathrm{dL}$ was found and a correlation of $\mathrm{r}=0.67$ with the reference device. Finally, using all four wavelengths a SEP of $6.16 \mathrm{mg} / \mathrm{dL}$ was found and a correlation of $\mathrm{r}=0.86$ with the reference device [117].

Similarly to BP estimation, using multiple wavelengths for 
BG estimations produced the lowest error rates [117]. Methods that required several sensors at multiple sites showed similar error rates [113] to methods with one device. Finally, deep learning as a method for feature extraction may be advantageous for BG estimation and should be explored further.

\section{Drug Delivery Monitoring}

Adhikari et al. developed a multi-wavelength transmission mode PPG method for the monitoring of drug delivery. They examined the use of Gold Nanorods, Quinine and Amphotericin $\mathrm{B}$ in mice possessing absorption peaks of $805 \mathrm{~nm}$, $355 \mathrm{~nm}$ and $355 \mathrm{~nm}$, respectively. Blood samples were collected from the mice after each PPG reading. Estimates were calculated using the pulsatile and non-pulsatile components of the signal to determine the extinction change due to pulsation at each wavelength using the Beer-Lambert law. The results showed that Gold Nanorods had a correlation of $r=0.94$ with the blood samples, Quinine had a correlation of $r=0.96$ and Amphotericin B had a correlation of $r=0.88$. This methodology could be used to monitor the circulation of molecular drugs and therapeutic nanoparticles having variable circulation halflives and could be applicable to a wide range of optically active drugs and nanoparticles [24]-[26].

\section{Discussion and Recommendations}

Multi-wavelength PPG shows promising signs of becoming a viable method for remote physiological monitoring as well as an alternative to ECG for cardiovascular monitoring. The selection of wavelengths used in PPG sensing is a compromise. It appears that green light $(492-577 \mathrm{~nm})$ produces the best generalized modulation, however, multi-wavelength approaches for HR, blood pressure and blood glucose estimations have been shown to out-perform single-wavelength approaches. Multi-wavelength approaches in clinical applications are not unique to PPG sensing. Narrow-band imaging for gastrointestinal endoscopy has seen improvements from white light endoscopy using blue and green light due to their varying interactions with blood and tissue. Blue light (400-430nm) penetrates to the depth of the capillaries in the superficial mucosa, while the green light $(525-555 \mathrm{~nm})$ penetrates deeper into the mucosa [120]. With the use of multiple wavelengths, the accuracy, robustness and generalizability of PPG sensing could be dramatically increased.

The findings, albeit limited, are conclusive that skin temperature affects PPG sensing which is concerning since the number of PPG studies that include skin temperature as a factor is small. There has been no research to the best of the authors' knowledge exploring the combination of motion artifacts, cold skin temperatures and higher skin melanin content. Data and insights from studies with combined factors could support the development of more robust solutions for continuous PPG sensing.

With small study sizes, anecdotal evidence and conflicting findings, understanding of the magnitude and scope of the potential inaccuracies of current PPG sensing due to skin melanin content is unclear. This is a concerning problem given that $80 \%$ of the world population are individuals with pigmented skin [121] and it has been projected that by 2035 half of the black population in USA will be affected by CVDs [122]. In order to address this problem researchers and industry professionals need to increase the diversity of subjects in validation studies to have proportional representation.

Current studies exploring skin melanin content tend to have smaller numbers of participants with darker skin tones [51], [53], [114] raising concerns of misleading conclusions [64], [86]. Bent et al. was the only study, to the best of the authors' knowledge, to have proportional distribution of skin tones [52], [123]. In addition, the current practice of classifying skin tone using the Fitzpatrick Skin Type Scale or the Von Luschan's chromatic scale, is a subjective process that may vary based on the administrator. It has been suggested that an objective approach to skin tone classification using a spectrophotometer should be employed as the "gold standard" to eliminate the shortcomings of the current practice [86], however spectrophotometers are expensive preventing wide-spread adoption, and there is evidence that "skin color evaluation with a spectrophotometer is correlated with visual skin tone assessment" and that "in both objective and subjective measurement methods, human error may be introduced through improper measurement methodology" [123].

There have been cases of racial bias, due to lack of proportional representation in validation studies, appearing in the surrounding disciplines. In the medical field, students have been petitioning to remove the "white skin bias" from medical textbooks as an extensive list of skin conditions, such as meningococcemia, appear different in patients with darker skin tones which are not accounted for in the texts [124], [125]. More generally, there is an increased awareness of cases of algorithmic bias against black individuals. Such cases include a healthcare prediction algorithm, used by more than 200 million patients in USA, that was less likely to refer equally sick black patients than white patients to programs aimed to improve care for patients with complex needs [126]. Additionally, in the optical engineering field, there are anecdotal examples of automatic taps and soap dispensers not working for individuals with darker skin tones [127].

There have been promising developments in motion artifact reduction using multi-wavelengths. Using IR light as a motion reference [116] allows for a more efficient solution as motion sensors such as accelerometers are not required as well as algorithmic approaches using several wavelengths [72]. Research in single-wavelength PPG sensing has explored the use of machine learning and deep learning models, such as Convolutional Neural Networks and Long Short-Term Memory networks, to accurately and robustly remove motion artifacts and estimate heart rate [128]-[130] and blood pressure [131]. This methodology would be well suited to multi-wavelength PPG sensing and should be explored further. Studies, however, lacked the exploration of combined adverse features in their experiments such as skin tone and skin temperature which could identify weaknesses in the proposed methodology.

As research into the field grows, standardization of reporting is of paramount importance in order to produce results that can be replicated and compared. Nelson et al. have produced a robust descriptive reporting protocol which if used would 
standardize the study design, technological factors, participant characteristics as well as data analysis, data reporting and data transparency [64]. It is also recommended that when using consumer-grade PPG sensing devices or off-the-shelf hardware components, accurate and complete information, such as software and firmware versions, should be given in order to allow the replication of experiments [132].

\section{CONCLUSION}

In this paper, we have presented a comprehensive review on multi-wavelength PPG sensors, encompassing state-of-theart research work and recommending potential directions for future developments with an emphasis on data collection protocols. In the first two sections theoretical details are given regarding the workings of PPG sensing and the optical properties of skin and blood. Additionally, biological factors that affect PPG sensing, such as skin melanin content and skin temperature, are explored showing conflicting findings highlighting the importance for these topics to be explored in greater detail. Multi-wavelength PPG solutions involve design considerations such as measurement site, contact force and sensor geometry as well as data collection protocols were explored to aid the decision process for future research. Finally, state-of-the-art multi-wavelength motion artifact reduction and physiological monitoring methods were summarized showing promising results highlighting the breadth of applications that multi-wavelength PPG sensing is capable of.

\section{ACKNOWLEDGMENT}

D. Ray thanks Nicholas C. S. Ray and Iris Ray for their unconditional support throughout his academic ventures.

\section{RefERENCES}

[1] Y. T. Zhang, "Editorial: Health engineering for urgent challenges in cardiovascular disease," IEEE Reviews in Biomedical Engineering, vol 13. Institute of Electrical and Electronics Engineers, pp. 3-4, 2020, doi: 10.1109/RBME.2019.2959113.

[2] A. Alzahrani, S. Hu, and V. Azorin-Peris, "A comparative study of physiological monitoring with a wearable opto-electronic patch sensor (OEPS) for motion reduction," Biosensors, vol. 5, no. 2, pp. 288-307, 2015, doi: 10.3390/bios5020288.

[3] D. Castaneda, A. Esparza, M. Ghamari, C. Soltanpur, and H. Nazeran, "A review on wearable photoplethysmography sensors and their potential future applications in health care," Int. J. Biosens. Bioelectron., vol. 4, no. 4, 2018, doi: 10.15406/ijbsbe.2018.04.00125.

[4] CCS Insight, "Optimistic outlook for wearables," CSS Insight, 2019. [Online]. Available: www.ccsinsight.com/press/company-news/ optimistic-outlook-for-wearables/ Accessed on: Mar. 30, 2021

[5] D. Biswas, N. Simoes-Capela, C. Van Hoof, and N. Van Helleputte, "Heart rate estimation from wrist-worn photoplethysmography: a review," IEEE Sens. J., vol. 19, no. 16, pp. 6560-6570, 2019, doi: 10.1109/JSEN.2019.2914166.

[6] J. Allen, "Photoplethysmography and its application in clinical physiological measurement," Physiol. Meas., vol. 28, no. 3, 2007, doi: 10.1088/0967-3334/28/3/R01

[7] A. B. Hertzman, "Photoelectric plethysmography of the fingers and toes in man," Proc. Soc. Exp. Biol. Med., vol. 37, no. 3, pp. 529-534, Dec. 1937, doi: 10.3181/00379727-37-9630.

[8] T. Pereira et al., "Photoplethysmography based atrial fibrillation detection: a review," npj Digital Medicine, vol. 3, no. 1. Nature Research, pp. 1-12, 01-Dec-2020, doi: 10.1038/s41746-019-0207-9.

[9] T. Tamura, "Current progress of photoplethysmography and SPO2 for health monitoring," Biomedical Engineering Letters, vol. 9, no. 1. 2019, doi: 10.1007/s13534-019-00097-w.
[10] P. H. Charlton et al., "Breathing rate estimation from the electrocardiogram and photoplethysmogram: A Review," IEEE Rev. Biomed. Eng., vol. 11, pp. 2-20, 2018, doi: 10.1109/RBME.2017.2763681.

[11] Y. K. Qawqzeh, "The analysis of PPG time indices to predict aging and atherosclerosis," in Intelligent Computing Paradigm and Cutting-edge Technologies, Springer, Cham, 2020, pp. 218-225.

[12] G. Wang, M. Atef, and Y. Lian, "Towards a continuous non-invasive cuffless blood pressure monitoring system using PPG: systems and circuits review," IEEE Circuits Syst. Mag., vol. 18, no. 3, pp. 6-26, Jul. 2018, doi: 10.1109/MCAS.2018.2849261.

[13] M. Elgendi et al., "The use of photoplethysmography for assessing hypertension," npj Digit. Med., vol. 2, no. 1, pp. 1-11, Dec. 2019, doi 10.1038/s41746-019-0136-7.

[14] N. Mangathayaru, B. P. Rani, V. Janaki, L. S. Kotturi, M. Vallabhapurapu, and G. Vikas, "Heart rate variability for predicting coronary heart disease using photoplethysmography," in Proceedings of the 4th International Conference on IoT in Social, Mobile, Analytics and Cloud, ISMAC 2020, 2020, pp. 664-671, doi: 10.1109/ISMAC49090.2020.9243316.

[15] N. Pinheiro et al., "Can PPG be used for HRV analysis?," in Proceedings of the Annual International Conference of the IEEE Engineering in Medicine and Biology Society, EMBS, 2016, vol. 2016-Octob, pp. 2945-2949, doi: 10.1109/EMBC.2016.7591347.

[16] C. Brüser, C. H. Antink, T. Wartzek, M. Walter, and S. Leonhardt, "Ambient and unobtrusive cardiorespiratory monitoring techniques," IEEE Rev. Biomed. Eng., vol. 8, pp. 30-43, 2015, doi: 10.1109/RBME.2015.2414661

[17] T. Rukasha, S. I. Woolley, T. Kyriacou, and T. Collins, "Evaluation of wearable electronics for epilepsy: a systematic review," Electron., vol. 9, no. 6, pp. 1-16, Jun. 2020, doi: 10.3390/electronics9060968.

[18] M. K. Uçar, S. Örenç, M. R. Bozkurt, and C. Bilgin, "Evaluation of the relationship between chronic obstructive pulmonary disease and photoplethysmography signal," in 2017 Medical Technologies National Conference, 2017, pp. 1-5, doi: 10.1109/TIPTEKNO.2017.8238032.

[19] P. Schmidt, A. Reiss, R. Dürichen, and K. Van Laerhoven, "Wearablebased affect recognition-a review," Sensors (Switzerland), vol. 19, no. 19. MDPI AG, 2019, doi: 10.3390/s19194079.

[20] P. H. Charlton, P. Celka, B. Farukh, P. Chowienczyk, and J. Alastruey, "Assessing mental stress from the photoplethysmogram: A numerical study," Physiol. Meas., vol. 39, no. 5, May 2018, doi: 10.1088/13616579/aabe6a.

[21] M. Shokoueinejad et al., "Sleep apnea: A review of diagnostic sensors, algorithms, and therapies," Physiological Measurement, vol. 38, no. 9. Institute of Physics Publishing, pp. R204-R252, 18-Aug-2017, doi: 10.1088/1361-6579/aa6ec6.

[22] H. Scott, L. Lack, and N. Lovato, "A systematic review of the accuracy of sleep wearable devices for estimating sleep onset," Sleep Medicine Reviews, vol. 49. W.B. Saunders Ltd, p. 101227, 01-Feb-2020, doi: 10.1016/j.smrv.2019.101227.

[23] S. Habbu, M. Dale, and R. Ghongade, "Estimation of blood glucose by non-invasive method using photoplethysmography," Sadhana - Acad. Proc. Eng. Sci., vol. 44, no. 6, pp. 1-14, Jun. 2019, doi: 10.1007/s12046019-1118-9.

[24] P. Adhikari, I. B. Magaña, and P. D. O'Neal, "Multi-wavelength pulse plethysmography for real-time drug delivery monitoring," in Optical Diagnostics and Sensing XIV: Toward Point-of-Care Diagnostics, 2014, vol. 8951, p. 89510P, doi: 10.1117/12.2040064.

[25] P. Adhikari, W. Eklund, and D. P. O'Neal, "Non-invasive in vivo monitoring of circulating amphotericin $b$ using multi-wavelength photoplethysmography," in Optical Diagnostics and Sensing XV: Toward Point-of-Care Diagnostics, 2015, vol. 9332, p. 93320H, doi: 10.1117/12.2083798.

[26] P. Adhikari, W. Eklund, E. A. Sherer, and D. P. O'Neal, “Assessment of multi-wavelength pulse photometry for non-invasive dose estimation of circulating drugs and nanoparticles," in Optical Diagnostics and Sensing XVI: Toward Point-of-Care Diagnostics, 2016, vol. 9715, p. 971500, doi: $10.1117 / 12.2213455$.

[27] W. Montagna, A. M. Kligman, and K. S. Carlisle, Atlas of normal human skin. 1992.

[28] A. N. Bashkatov, E. A. Genina, V. I. Kochubey, and V. V. Tuchin, "Optical properties of human skin, subcutaneous and mucous tissues in the wavelength range from 400 to $2000 \mathrm{~nm}$," J. Phys. D. Appl. Phys., vol. 38 , no. 15 , pp. 2543-2555, Aug. 2005, doi: 10.1088/0022$3727 / 38 / 15 / 004$

[29] M. Brenner and V. J. Hearing, "The protective role of melanin against UV damage in human skin," Photochemistry and Photobiology, vol. 84, 
no. 3. NIH Public Access, pp. 539-549, May 2008, doi: 10.1111/j.17511097.2007.00226.x.

[30] G. Zonios, J. Bykowski, and N. Kollias, "Skin melanin, hemoglobin, and light scattering properties can be quantitatively assessed in vivo using diffuse reflectance spectroscopy," J. Invest. Dermatol., vol. 117, no. 6, pp. 1452-1457, 2001, doi: 10.1046/j.0022-202x.2001.01577.x.

[31] B. Müller et al., "High-resolution tomographic imaging of microvessels," Dev. X-Ray Tomogr. VI, vol. 7078, p. 70780B, Sep. 2008, doi: 10.1117/12.794157.

[32] T. Lister, P. A. Wright, and P. H. Chappell, "Optical properties of human skin,” J. Biomed. Opt., vol. 17, no. 9, p. 0909011, Sep. 2012, doi: 10.1117/1.jbo.17.9.090901.

[33] R. R. Anderson and J. A. Parrish, "The optics of human skin," J. Invest. Dermatol., vol. 77, no. 1, pp. 13-19, 1981, doi: 10.1111/15231747.ep12479191.

[34] M. Lemay, M. Bertschi, J. Sola, P. Renevey, J. Parak, and I. Korhonen, "Application of optical heart rate monitoring," in Wearable Sensors: Fundamentals, Implementation and Applications, Elsevier Inc., 2014, pp. $105-129$.

[35] C. R. Simpson, M. Kohl, M. Essenpreis, and M. Cope, "Near-infrared optical properties of ex vivo human skin and subcutaneous tissues measured using the Monte Carlo inversion technique," Phys. Med. Biol., vol. 43, no. 9, pp. 2465-2478, 1998, doi: 10.1088/0031-9155/43/9/003.

[36] P. Taroni, A. Pifferi, A. Torricelli, D. Comelli, and R. Cubeddu, "In vivo absorption and scattering spectroscopy of biological tissues," Photochem. Photobiol. Sci., vol. 2, no. 2, pp. 124-129, 2003, doi 10.1039/b209651j.

[37] J. Yao and S. Warren, "A novel algorithm to separate motion artifacts from photoplethysmographic signals obtained with a reflectance pulse oximeter," in Annual International Conference of the IEEE Engineering in Medicine and Biology - Proceedings, 2004, vol. 26 III, pp. 2153-2156, doi: 10.1109/iembs.2004.1403630.

[38] L. Linberg and P. Öberg, "Photoplethysmography: Part 2 Influence of light source wavelength," Med. Biol. Eng. Comput., no. January, pp. 48-49, 1991, doi: 10.1007/bf02446295.

[39] A. Alzahrani et al., "A multi-channel opto-electronic sensor to accurately monitor heart rate against motion artefact during exercise," Sensors (Switzerland), vol. 15, no. 10, pp. 25681-25702, Oct. 2015, doi: $10.3390 / \mathrm{s} 151025681$.

[40] V. Vizbara, A. Solosenko, D. Stankevicius, and V. Marozas, "Comparison of green, blue and infrared light in wrist and forehead photoplethysmography," Biomed. Eng. 2014, pp. 78-81, doi: 10.1109/IEMBS.2008.4649649.

[41] J. Spigulis, L. Gailite, A. Lihachev, and R. Erts, "Simultaneous recording of skin blood pulsations at different vascular depths by multiwavelength photoplethysmography," in Applied Optics, 2007, vol. 46, no. 10, pp. 1754-1759, doi: 10.1364/AO.46.001754.

[42] S. Han, D. Roh, J. Park, and H. Shin, "Design of multi-wavelength optical sensor module for depth-dependent photoplethysmography," Sensors (Switzerland), vol. 19, no. 24, Dec. 2019, doi: 10.3390/s19245441.

[43] D. Barolet, "Light-emitting diodes (LEDs) in dermatology," Semin. Cutan. Med. Surg., vol. 27, no. 4, pp. 227-238, Dec. 2008, doi: 10.1016/j.sder.2008.08.003.

[44] A. L. Ries, L. M. Prewitt, and J. J. Johnson, "Skin color and ear oximetry," Chest, vol. 96, no. 2, pp. 287-290, 1989, doi: 10.1378/chest.96.2.287.

[45] J. R. Feiner, J. W. Severinghaus, and P. E. Bickler, "Dark skin decreases the accuracy of pulse oximeters at low oxygen saturation: The effects of oximeter probe type and gender," Anesth. Analg., vol. 105, no. SUPPL. 6, 2007, doi: 10.1213/01.ane.0000285988.35174.d9.

[46] P. E. Bickler, J. R. Feiner, and J. W. Severinghaus, "Effects of skin pigmentation on pulse oximeter accuracy at low saturation," Anesthesiology, vol. 102 , no. 4, pp. 715-719, 2005, doi: 10.1097/00000542200504000-00004.

[47] M. W. Sjoding, R. P. Dickson, T. J. Iwashyna, S. E. Gay, and T. S. Valley, "Racial bias in pulse oximetry measurement," https://doi.org/10.1056/NEJMc2029240, vol. 383, no. 25, pp. 2477-2478, Dec. 2020, doi: 10.1056/NEJMC2029240.

[48] P. A. Bothma et al., "Accuracy of pulse oximetry in pigmented patients," South African Med. J., vol. 86, no. 5 SUPPL., pp. 594-596, 1996.

[49] E. E. Foglia et al., "The effect of skin pigmentation on the accuracy of pulse oximetry in infants with hypoxemia," J. Pediatr., vol. 182, pp. 375-377.e2, Mar. 2017, doi: 10.1016/j.jpeds.2016.11.043.

[50] W. Cui, L. E. Ostrander, and B. Y. Lee, "In vivo reflectance of blood and tissue as a function of light wavelength," IEEE Trans. Biomed. Eng., vol. 37, no. 6, pp. 632-639, 1990, doi: 10.1109/10.55667.
[51] L. Yan, S. Hu, A. Alzahrani, S. Alharbi, and P. Blanos, "A multiwavelength opto-electronic patch sensor to effectively detect physiological changes against human skin types," Biosensors, vol. 7, no. 2, Jun. 2017, doi: 10.3390/bios7020022.

[52] B. Bent, B. A. Goldstein, W. A. Kibbe, and J. P. Dunn, "Investigating sources of inaccuracy in wearable optical heart rate sensors," npj Digit. Med., vol. 3, no. 1, p. 18, Dec. 2020, doi: 10.1038/s41746-020-0226-6.

[53] B. A. Fallow, T. Tarumi, and H. Tanaka, "Influence of skin type and wavelength on light wave reflectance," J. Clin. Monit. Comput., vol. 27, no. 3, pp. 313-317, Jun. 2013, doi: 10.1007/s10877-013-9436-7.

[54] A. Shcherbina et al., "Accuracy in wrist-worn, sensor-based measurements of heart rate and energy expenditure in a diverse cohort," J. Pers. Med., vol. 7, no. 2, pp. 1-12, Jun. 2017, doi: 10.3390/jpm7020003.

[55] S. P. Preejith, A. Alex, J. Joseph, and M. Sivaprakasam, "Design, development and clinical validation of a wrist-based optical heart rate monitor," 2016 IEEE Int. Symp. Med. Meas. Appl. MeMeA 2016 Proc., Aug. 2016, doi: 10.1109/MEMEA.2016.7533786.

[56] I. C. Jeong, H. Yoon, H. Kang, and H. Yeom, "Effects of skin surface temperature on photoplethysmograph," J. Healthc. Eng., vol. 5, no. 4, pp. 429-438, 2014, doi: 10.1260/2040-2295.5.4.429.

[57] K. Budidha and P. A. Kyriacou, "In vivo investigation of ear canal pulse oximetry during hypothermia," J. Clin. Monit. Comput., vol. 32, no. 1, pp. 97-107, Feb. 2018, doi: 10.1007/s10877-017-9975-4.

[58] A. C. Ralston, R. K. Webb, and W. B. Runciman, "Potential errors in pulse oximetry: I. pulse oximeter evaluation," Anaesthesia, vol. 46, no. 3, pp. 202-206, 1991, doi: 10.1111/j.1365-2044.1991.tb09410.x.

[59] Y. Maeda, M. Sekine, T. Tamura, A. Moriya, T. Suzuki, and K. Kameyama, "Comparison of reflected green light and infrared photoplethysmography," in Proceedings of the 30th Annual International Conference of the IEEE Engineering in Medicine and Biology Society, EMBS'08 - "Personalized Healthcare through Technology," 2008, pp. 2270-2272, doi: 10.1109/iembs.2008.4649649.

[60] Y. Maeda, M. Sekine, and T. Tamura, "The advantages of wearable green reflected photoplethysmography," J. Med. Syst., vol. 35, no. 5, pp. 829-834, Oct. 2011, doi: 10.1007/s10916-010-9506-z.

[61] B. Askarian, K. Jung, and J. W. Chong, "Monitoring of heart rate from photoplethysmographic signals using a Samsung Galaxy Note8 in underwater environments," Sensors (Switzerland), vol. 19, no. 13, p. 2846, Jul. 2019, doi: 10.3390/s19132846.

[62] L. Menghini, E. Gianfranchi, N. Cellini, E. Patron, M. Tagliabue, and M. Sarlo, "Stressing the accuracy: wrist-worn wearable sensor validation over different conditions," Psychophysiology, vol. 56, no. 11, Nov. 2019, doi: 10.1111/psyp.13441.

[63] J. Fine et al., "Sources of inaccuracy in photoplethysmography for continuous cardiovascular monitoring," Biosens. 2021, Vol. 11, Page 126, vol. 11, no. 4, p. 126, Apr. 2021, doi: 10.3390/BIOS11040126.

[64] B. W. Nelson, C. A. Low, N. Jacobson, P. Areán, J. Torous, and N. B. Allen, "Guidelines for wrist-worn consumer wearable assessment of heart rate in biobehavioral research," npj Digit. Med., vol. 3, no. 1, pp. 1-9, Dec. 2020, doi: 10.1038/s41746-020-0297-4.

[65] S. Gillinov et al., "Variable accuracy of wearable heart rate monitors during aerobic exercise," Med. Sci. Sports Exerc., vol. 49, no. 8, pp. 1697-1703, Aug. 2017, doi: 10.1249/MSS.0000000000001284.

[66] R. Wang et al., "Accuracy of wrist-worn heart rate monitors," JAMA Cardiol., vol. 2, no. 1, pp. 104-106, Jan. 2017, doi: 10.1001/jamacardio.2016.3340.

[67] G. Cosoli, S. Spinsante, and L. Scalise, "Wrist-worn and chest-strap wearable devices: systematic review on accuracy and metrological characteristics," Measurement: Journal of the International Measurement Confederation, vol. 159. Elsevier B.V., p. 107789, Jul. 15, 2020, doi: 10.1016/j.measurement.2020.107789.

[68] L. Asare, E. Kviesis-Kipge, A. Grabovskis, U. Rubins, J. Spigulis, and R. Erts, "Multi-spectral photoplethysmography biosensor," in Optical Sensors 2011; and Photonic Crystal Fibers V, May 2011, vol. 8073, p. 80731Z, doi: $10.1117 / 12.887176$.

[69] P. Blanos, S. Hu, D. Mulvaney, and S. Alharbi, "An applicable approach for extracting human heart rate and oxygen saturation during physical movements using a multi-wavelength illumination optoelectronic sensor system," in Society of Photo-Optical Instrumentation Engineers, Feb. 2018, p. 27, doi: $10.1117 / 12.2287854$.

[70] S. Sen Gupta, S. Hossain, C. A. Haque, and K. D. Kim, "InVivo estimation of glucose level using PPG signal," Int. Conf. ICT Converg., vol. 2020-October, pp. 733-736, Oct. 2020, doi: 10.1109/ICTC49870.2020.9289629.

[71] K. M. Warren, J. R. Harvey, K. H. Chon, and Y. Mendelson, "Improving pulse rate measurements during random motion using a wearable 
multichannel reflectance photoplethysmograph," Sensors (Switzerland), vol. 16, no. 3, Mar. 2016, doi: 10.3390/s16030342.

[72] J. Lee, M. Kim, H. K. Park, and I. Y. Kim, "Motion artifact reduction in wearable photoplethysmography based on multi-channel sensors with multiple wavelengths," Sensors (Switzerland), vol. 20, no. 5, Mar. 2020, doi: $10.3390 / \mathrm{s} 20051493$.

[73] C. C. Chang, C. T. Wu, B. Il Choi, and T. J. Fang, "MW-PPG sensor: an on-chip spectrometer approach," Sensors (Switzerland), vol. 19, no. 17, Sep. 2019, doi: 10.3390/s19173698.

[74] S.-H. Chen, Y.-C. Chuang, and C.-C. Chang, "Development of a portable all-wavelength PPG sensing device for robust adaptive-depth measurement: a spectrometer approach with a hydrostatic measurement example," Sensors 2020, Vol. 20, Page 6556, vol. 20, no. 22, p. 6556, Nov. 2020, doi: 10.3390/S20226556.

[75] M. Leier, K. Pilt, D. Karai, and G. Jervan, "Smart photoplethysmographic sensor for pulse wave registration at different vascular depths," in Proceedings of the Annual International Conference of the IEEE Engineering in Medicine and Biology Society, EMBS, 2015, vol. 2015Novem, pp. 1849-1852, doi: 10.1109/EMBC.2015.7318741.

[76] Y. Maeda, M. Sekine, and T. Tamura, "Relationship between measurement site and motion artifacts in wearable reflected photoplethysmography," in Journal of Medical Systems, Oct. 2011, vol. 35, no. 5, pp. 969-976, doi: 10.1007/s10916-010-9505-0.

[77] Y. Mendelson and C. Pujary, "Measurement site and photodetector size considerations in optimizing power consumption of a wearable reflectance pulse oximeter," in Annual International Conference of the IEEE Engineering in Medicine and Biology - Proceedings, 2003, vol. 4, pp. 3016-3019, doi: 10.1109/iembs.2003.1280775.

[78] T. Tamura, Y. Maeda, M. Sekine, and M. Yoshida, "Wearable photoplethysmographic sensors-past and present," Electron. , vol. 3, no. 2, pp. 282-302, 2014, doi: 10.3390/electronics3020282.

[79] V. Hartmann, H. Liu, F. Chen, Q. Qiu, S. Hughes, and D. Zheng, "Quantitative comparison of photoplethysmographic waveform characteristics: effect of measurement site," Front. Physiol., vol. 10, no. MAR, p. 198, Mar. 2019, doi: 10.3389/fphys.2019.00198.

[80] J. Liu, B. P. Yan, Y. T. Zhang, X. R. Ding, P. Su, and N. Zhao, "Multi-wavelength photoplethysmography enabling continuous blood pressure measurement with compact wearable electronics," IEEE Trans. Biomed. Eng., vol. 66, no. 6, pp. 1514-1525, Jun. 2019, doi: 10.1109/TBME.2018.2874957.

[81] S. K. Longmore, G. Y. Lui, G. Naik, P. P. Breen, B. Jalaludin, and G. D. Gargiulo, "A comparison of reflective photoplethysmography for detection of heart rate, blood oxygen saturation, and respiration rate at various anatomical locations," Sensors (Switzerland), vol. 19, no. 8, Apr. 2019, doi: 10.3390/s19081874.

[82] S. Lee, H. Shin, and C. Hahm, "Effective PPG sensor placement for reflected red and green light, and infrared wristband-type photoplethysmography," in International Conference on Advanced Communication Technology, ICACT, Mar. 2016, vol. 2016-March, pp. 556-558, doi: 10.1109/ICACT.2016.7423470.

[83] E. Geun, H. Heo, K. C. Nam, and Y. Huh, "Measurement site and applied pressure consideration in wrist photoplethysmography," 23rd Int. Tech. Conf. Circuits Systems Comput. Commun. ITCCSCC 2008, vol. 51, no. 3, pp. 1129-1132, 2008, doi: 10.1080/10635150290069913.

[84] Polar Research and Technology, "Polar precision prime OHR," Polar Res. Technol., 2019, Accessed: Mar. 30, 2021. [Online]. Available: https://www.polar.com/sites/default/files/static/science/whitepapers/polar-precision-prime-white-paper.pdf

[85] T. Rukasha, S. I. Woolley, and T. Collins, "Poster: heart rate performance of a medical-grade data streaming wearable device," in Proceedings - 2020 IEEE/ACM International Conference on Connected Health: Applications, Systems and Engineering Technologies, CHASE 2020, Dec. 2020, pp. 12-13, doi: 10.1145/3384420.3431776.

[86] P. J. Colvonen, P. N. DeYoung, N. O. A. Bosompra, and R. L. Owens, "Limiting racial disparities and bias for wearable devices in health science research," Sleep, vol. 43, no. 10. Sep. 07, 2020, doi: 10.1093/sleep/zsaa159.

[87] U.S. Food and Drug Administration, "510(k) premarket notification," U.S. Food and Drug Administration, 2021. www.accessdata.fda.gov/ scripts/cdrh/cfdocs/cfpmn/pmn.cfm?ID=K172935 (accessed Apr. 09, 2021).

[88] Fitbit, "Important safety and product information," Fitbit, 2021. www.fitbit.com/in/legal/safety-instructions (accessed Mar. 30, 2021).

[89] Garmin, "Accuracy," Garmin, 2021. www.garmin.com/en-US/legal/ atdisclaimer/ (accessed Mar. 30, 2021).
[90] Apple, "Important safety information for Apple Watch - Apple Support," Apple, 2021. support.apple.com/en-gb/guide/watch/apdcf2ff54e9/ watchos (accessed Mar. 30, 2021).

[91] Analog Devices, "ADPD188GG data sheet," 2020. Accessed: Apr. 09, 2021. [Online]. Available: www.analog.com/media/en/technicaldocumentation/data-sheets/adpd188gg.pdf

[92] Analog Devices, "ADPD144RI data sheet," 2019. Accessed: Apr. 09, 2021. [Online]. Available: www.analog.com/media/en/technicaldocumentation/data-sheets/ADPD144RI.pdf

[93] Maxim Integrated, "MAX30101 data sheet," 2020. Accessed: Apr. 09, 2021. [Online]. Available: datasheets.maximintegrated.com/en/ds/ MAX30101.pdf

[94] Maxim Integrated, "MAX86150 data sheet," 2018. Accessed: Apr. 09, 2021. [Online]. Available: datasheets.maximintegrated.com/en/ds/ MAX86150.pdf

[95] Maxim Integrated, "MAX86916 data sheet," 2019. Accessed: Apr. 09, 2021. [Online]. Available: datasheets.maximintegrated.com/en/ds/ MAX86916.pdf

[96] OSRAM, "SFH 7072 OSRAM opto semiconductors," 2020. www.osram.com/ecat/BIOFY\%C2\%AE\%20SFH\%207072/com/en/ class_pim_web_catalog_103489/prd_pim_device_2220016/ (accessed Apr. 09, 2021).

[97] OSRAM, "SFH 7050 OSRAM opto semiconductors," 2020. www.osram.com/ecat/BIOFY\%C2\%AE\%20SFH\%207050/com/en/ class_pim_web_catalog_103489/prd_pim_device_2220012/ (accessed Apr. 09, 2021).

[98] Y. H. Kao, P. C. P. Chao, and C. L. Wey, "Design and validation of a new ppg module to acquire high-quality physiological signals for highaccuracy biomedical sensing," IEEE J. Sel. Top. Quantum Electron., vol. 25, no. 1, p. 8470924, Feb. 2019, doi: 10.1109/JSTQE.2018.2871604.

[99] H. J. Baek, S. Y. Sim, J. S. Kim, and K. S. Park, "Effect of sensor configurations on indirect-contact photoplethysmogram measurement system," in 2010 5th Cairo International Biomedical Engineering Conference, CIBEC 2010, 2010, pp. 244-246, doi: 10.1109/CIBEC.2010.5716070.

[100] B. Bent and J. P. Dunn, "Optimizing sampling rate of wrist-worn optical sensors for physiologic monitoring," J. Clin. Transl. Sci., pp. 1-8, 2020, doi: $10.1017 /$ cts.2020.526.

[101] Analog Devices, "ADPD4000/ADPD4001 data sheet," 2019. Accessed: Apr. 09, 2021. [Online]. Available: www.analog.com/media/en/ technical-documentation/data-sheets/ADPD4000-4001.pdf

[102] Analog Devices, "ADPD4100/ADPD4101 data sheet," 2020. Accessed: Apr. 09, 2021. [Online]. Available: www.analog.com/media/en/ technical-documentation/data-sheets/adpd4100-4101.pdf

[103] Maxim Integrated, "MAX30110 data sheet," 2017. Accessed: Apr. 09, 2021. [Online]. Available: datasheets.maximintegrated.com/en/ds/ MAX30110.pdf

[104] Maxim Integrated, "MAXM86146 data sheet," 2020. Accessed: Apr. 09, 2021. [Online]. Available: datasheets.maximintegrated.com/en/ds/ MAXM86146.pdf

[105] Texas Instruments, "AFE4950 data sheet," 2020. Accessed: Apr. 09, 2021. [Online]. Available: www.ti.com/lit/ds/symlink/afe4950.pdf?ts= 1617894847053

[106] Texas Instruments, "AFE44S30 data sheet," 2019. Accessed: Apr. 09, 2021. [Online]. Available: www.ti.com/lit/ds/symlink/afe44s30.pdf?ts= 1617973955101

[107] Texas Instruments, "AFE4900 data sheet," 2020. Accessed: Apr. 09, 2021. [Online]. Available: www.ti.com/lit/ds/symlink/afe4900.pdf?ts= 1617950577027

[108] Texas Instruments, "AFE4404 data sheet," 2020. Accessed: Apr. 09, 2021. [Online]. Available: www.ti.com/lit/ds/symlink/afe4404.pdf?ts= 1617893854742

[109] X. F. Teng and Y. T. Zhang, "The effect of contacting force on photoplethysmographic signals," Physiol. Meas., vol. 25, no. 5, pp. 1323-1335, Oct. 2004, doi: 10.1088/0967-3334/25/5/020.

[110] K. Matsumura, P. Rolfe, J. Lee, and T. Yamakoshi, "iPhone 4s photoplethysmography: which light color yields the most accurate heart rate and normalized pulse volume using the iPhysioMeter application in the presence of motion artifact?," PLoS One, vol. 9, no. 3, Mar. 2014 doi: 10.1371/journal.pone.0091205.

[111] J. Liu, Y. Li, X. R. Ding, W. X. Dai, and Y. T. Zhang, "Effects of cuff inflation and deflation on pulse transit time measured from ECG and multi-wavelength PPG," in Proceedings of the Annual International Conference of the IEEE Engineering in Medicine and Biology Society, EMBS, 2015, vol. 2015-Novem, pp. 5973-5976, doi: 10.1109/EMBC.2015.7319752.

[112] J. Liu, B. P.-Y. Yan, W.-X. Dai, X.-R. Ding, Y.-T. Zhang, and N. Zhao, "Multi-wavelength photoplethysmography method for skin arterial pulse 
extraction,” Biomed. Opt. Express, vol. 7, no. 10, p. 4313, Oct. 2016, doi: 10.1364/boe.7.004313.

[113] Z. Geng, F. Tang, Y. Ding, S. Li, and X. Wang, "Noninvasive continuous glucose monitoring using a multisensor-based glucometer and time series analysis," Sci. Reports 2017 71, vol. 7, no. 1, pp. 1-10, Oct. 2017, doi: 10.1038/s41598-017-13018-7.

[114] S. Pasta et al., "A novel multi-wavelength procedure for blood pressure estimation using opto-physiological sensor at peripheral arteries and capillaries," in Society of Photo-Optical Instrumentation Engineers, Feb. 2018, p. 39, doi: $10.1117 / 12.2287845$.

[115] S. Alharbi et al., "Oxygen saturation measurements from green and orange illuminations of multi-wavelength optoelectronic patch sensors," Sensors (Switzerland), vol. 19, no. 1, Jan. 2019, doi: 10.3390/s19010118.

[116] Y. Zhang et al., "Motion artifact reduction for wrist-worn photoplethysmograph sensors based on different wavelengths," Sensors (Switzerland), vol. 19, no. 3, Feb. 2019, doi: 10.3390/s19030673.

[117] V. P. Rachim and W. Y. Chung, "Wearable-band type visible-near infrared optical biosensor for non-invasive blood glucose monitoring," Sensors Actuators B Chem., vol. 286, pp. 173-180, May 2019, doi: 10.1016/J.SNB.2019.01.121.

[118] J. Liu et al., "PCA-based multi-wavelength photoplethysmography algorithm for cuffless blood pressure measurement on elderly subjects," IEEE J. Biomed. Heal. Informatics, pp. 1-1, Jun. 2020, doi: 10.1109/jbhi.2020.3004032.

[119] C. Y. Wang and K. T. Tang, "Active noise cancellation of motion artifacts in pulse oximetry using isobestic wavelength light source," in Proceedings - IEEE International Symposium on Circuits and Systems, 2011, pp. 1029-1032, doi: 10.1109/ISCAS.2011.5937744.

[120] S. Barbeiro, D. Libânio, R. Castro, M. Dinis-Ribeiro, and P. PimentelNunes, "Narrow-band imaging: clinical application in gastrointestinal endoscopy," GE Port. J. Gastroenterol., vol. 26, no. 1, p. 40, Dec. 2018, doi: $10.1159 / 000487470$.

[121] A. Adegbenro and S. Taylor, "Structural, physiological, functional, and cultural differences in skin of color," in Skin of Color, Springer New York, 2013, pp. 1-19.

[122] American Heart Association, "Cardiovascular disease a costly burden," Am. Hear. Assoc., vol. 91, pp. 399-404, 2017, doi: 1/17DS11775.

[123] B. Bent, O. M. Enache, B. Goldstein, W. Kibbe, and J. P. Dunn, "Reply: matters arising 'Investigating sources of inaccuracy in wearable optical heart rate sensors," npj Digital Medicine, vol. 4, no. 1. Nature Research, pp. 1-3, Dec. 01, 2021, doi: 10.1038/s41746-021-00409-4.

[124] C. Agu, "Petition: Medical schools must include BAME representation in clinical teaching," Change.org, 2020. www.change.org/p/gmcmedical-schools-must-include-bame-representation-in-clinical-teaching (accessed Mar. 30, 2021)

[125] M. Mukwende, "Mind the gap: A clinical handbook of signs and symptoms in black and brown skin," blackandbrownskin.co.uk, 2020. www.blackandbrownskin.co.uk/ (accessed Mar. 30, 2021).

[126] Z. Obermeyer, B. Powers, C. Vogeli, and S. Mullainathan, "Dissecting racial bias in an algorithm used to manage the health of populations," Science, vol. 366 , no. 6464 , pp. $447-453$, Oct. 2019 , doi: $10.1126 /$ science.aax 2342

[127] S. Fussell, “Why Can't This Soap Dispenser Identify Dark Skin?," GIZMODO, 2017. gizmodo.com/why-cant-this-soap-dispenseridentify-dark-skin-1797931773 (accessed Mar. 30, 2021).

[128] A. Reiss, I. Indlekofer, P. Schmidt, and K. Van Laerhoven, "Deep PPG: large-scale heart rate estimation with convolutional neural networks," Sensor, vol. 19, no. 14, pp. 1-27, 2019, doi: 10.3390/s19143079.

[129] L. G. Rocha et al., "Real-time HR estimation from wrist PPG using binary LSTMs," in BioCAS 2019 - Biomedical Circuits and Systems Conference, Proceedings, Oct. 2019, pp. 1-4, doi: 10.1109/BIOCAS.2019.8918726.

[130] H. Chung, H. Ko, H. Lee, and J. Lee, "Deep learning for heart rate estimation from reflectance photoplethysmography with acceleration power spectrum and acceleration intensity," IEEE Access, vol. 8, pp. 63390-63402, 2020, doi: 10.1109/ACCESS.2020.2981956.

[131] C. El-Hajj and P. A. Kyriacou, "A review of machine learning techniques in photoplethysmography for the non-invasive cuffless measurement of blood pressure," Biomedical Signal Processing and Control, vol. 58. Elsevier Ltd, p. 101870, Apr. 01, 2020, doi: 10.1016/j.bspc.2020.101870.

[132] S. I. Woolley, T. Collins, J. Mitchell, and D. Fredericks, "Investigation of wearable health tracker version updates," BMJ Heal. Care Informatics, vol. 26, no. 1, p. 100083, Oct. 2019, doi: 10.1136/bmjhci-2019-100083.

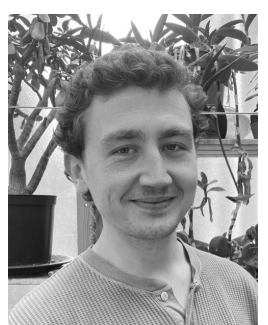

Daniel Ray is currently pursuing Ph.D. in the Department of Engineering at Manchester Metropolitan University, UK. His research interests include nature-inspired computing, wearable computing, health technologies and the ethics of technology. He has a MSc in Data Science at Manchester Metropolitan University, UK and a BSc in Computing at the University of Liverpool, UK. He is a Student Member of the IEEE and the British Computer Society.

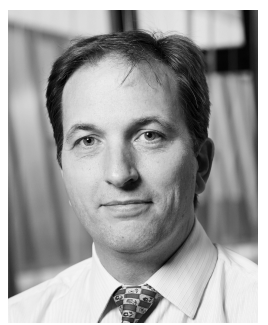

Tim Collins is a senior lecturer at Manchester Metropolitan University, UK, where he is the programme leader for Electrical and Electronic Engineering. He has a PhD in Electronic and Electrical Engineering from the University of Birmingham, UK, and is a Chartered Engineer (IET) and a Senior Member of the IEEE. His research interests are in the utilization of signal processing and image processing techniques, including machine learning, to applications including acoustics, communications, 3D computational geometry, extended reality and health technology.

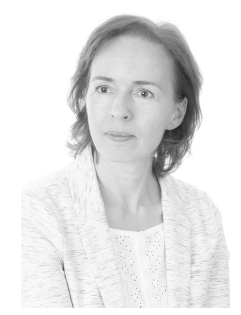

Sandra I. Woolley leads Software and Systems Engineering Research at Keele University, UK. She has a $\mathrm{PhD}$ in Electrical Engineering from Manchester University and is a Senior Member of the IEEE and a Fellow of the British Computer Society. She has long-standing research interests in wearable computing, sensing systems, and health technologies that encompass performance evaluations, patient monitoring applications, and system usability. She teaches computer science masters and undergraduate modules in User Interaction Design, Animation and Multimedia, and Professionalism and she chairs Faculty Research and School Taught Programme Ethics Committees.

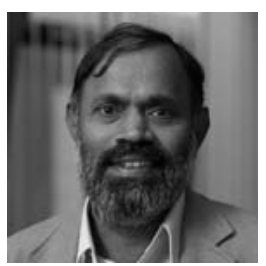

Prasad V. S. Ponnapalli is a senior lecturer at Manchester Metropolitan University, UK. He teaches Control Engineering, Industrial Automation and Cyber-Physical Systems at UG and $P G$ level. His research interests are intelligent control, industrial automation and applications of Al. He has a PhD in Electronic and Electrical Engineering from the Queen's University of Belfast, UK, and is a Member of the IEEE and the IET. 